\title{
Structural Inferences from First-Price Auction Experiments ${ }^{\dagger}$
}

\author{
Paul Pezanis-Christou \\ Institut d'Anàlisi Econòmica, CSIC \\ Campus Universitat Autonoma de Barcelona, \\ Bellaterra 08193,Barcelona, Spain
}

\author{
Andres Romeu \\ Departament de Fonaments de l'Anàlisi Econòmica, \\ Universitat d'Alacant, \\ San Vicent 03690, Alacant, Spain
}

November 19, 2002

\begin{abstract}
We use structural methods to assess equilibrium models of bidding with data from firstprice auction experiments. We identify conditions to test the Nash equilibrium models for homogenous and for heterogeneous constant relative risk aversion when bidders' private valuations are independent and uniformly drawn. The outcomes of our study indicate that behavior may have been affected by the procedure used to conduct the experiments and that the usual Nash equilibrium model for heterogeneous constant relative risk averse bidders does not consistently explain the observed overbidding. From an empirical standpoint, our analysis shows the possible drawbacks of overlooking the homogeneity hypothesis when testing symmetric equilibrium models of bidding and it puts in perspective the sensitivity of structural inferences to the available information.
\end{abstract}

Key Words: first-price auctions, private independent values, experimental data, structural econometric methods, Non Linear Least Squares, constant relative risk aversion

\footnotetext{
$\uparrow$ We thank Olivier Armantier, Jacob Goeree and participants at the ESA 2002 Conference (Strasbourg) for helpful comments. We are grateful to James Cox, Vernon Smith and James Walker for providing us with their data. Financial support from the European Commission through a EU-TMR ENDEAR Network grant (FMRX-CT98-0238) and from the Ministerio de Ciencia y Tecnologia (Grant BEC-2001-0980) is acknowledged. Remaining errors are ours.

E-mail addresses: Pezanis-Christou: ppc@iae.csic.es, Romeu: aromeu@fae.merlin.es
} 


\section{Introduction}

A large body of the experimental literature on auction markets draws its inferences from the testing of reduced form expressions of equilibrium predictions. In this paper we re-examine experimental data on symmetric first-price auctions with private independent valuations from a structural perspective. To the difference of the reduced form approach, which consists in estimating individual bid functions or in evaluating deviations from equilibrium predictions, the structural approach allows the assessment of complete equilibrium models by assuming that the observed variables are in equilibrium (Hendricks and Paarsch (1995), Laffont (1997)). From an empirical perspective, this equilibrium assumption remains difficult to check because the relevant data are usually unavailable to the researcher (e.g., the distribution of valuations or private signals and/or the number of active bidders). Therefore the structural analysis of field auction data typically consists in recovering the unobserved information from the available data by assuming bidders to act in a given equilibrium (Paarsch (1992), Donald and Paarsch (1993), Laffont, Ossard and Vuong (1995), Guerre, Perrigne and Vuong (2000) and Athey and Haile (2002)). ${ }^{1}$ Such an approach can be very useful for policy making (e.g., setting an optimal reserve price for the seller) but the inferences made remain conditional on the assumption that the recovered information is correct or equivalently, that the observed bids and prices are in the assumed equilibrium.

From an experimental perspective, as all the variables of the model studied are known to the researcher and are made explicit to the participating bidders, structural methods are well adapted to assess equilibrium models with laboratory data. In particular, they allow us to assess Vickrey's (1961) benchmark equilibrium model and two of its variations that are often referred to in the literature on first-price auction experiments with private independent valuations (Kagel (1995)).

\footnotetext{
${ }^{1}$ Li, Perrigne and Vuong (2000) and Campo, Perrigne and Vuong (2001) develop structural methods to analyze auctions in which bidders' valuations or signals are drawn from different distributions and/or are affiliated (i.e. locally positively correlated).
} 
Behavior in these experiments is often characterized by a significant overbidding (i.e., bidding above the risk neutral Nash equilibrium prediction) and is usually found to be well or best fitted by a Nash equilibrium model that assumes constant relative risk attitudes.

The simplest version of this model has been proposed by Cox, Roberson and Smith (1982), and is an extension of Vickrey's model for risk neutral bidders to account for homogenous constant relative risk attitudes (henceforth, the Risk Averse Symmetric Nash Equilibrium, RASNE model). They assess this model with experimental data and find that it explains well behavior in auctions with 3 bidders but not in auctions with 4 bidders or more, where behavior is characterized by a significant heterogeneity in the overbidding. Kagel, Harstad and Levin (1987) study first-price auctions with 6 bidders and find that the data is well fitted by the RASNE model in the aggregate but not at the individual level. Goeree, Holt and Palfrey (2002) analyze aggregate behavior in two-bidder first-price auctions with Quantal Response Equilibrium models, which combine a probabilistic choice function with an equilibrium condition on the consistency of bidders' actions and beliefs. They find that the hypothesis of homogenous constant relative risk aversion fits their data remarkably well. However, Quantal Response Equilibrium models assume that it is common knowledge to bidders that they make mistakes in implementing their best replies and that they optimally react to the errors of their rivals. Such an assumption introduces a stochastic element in the bidders' reaction functions which compounding effect may lead to equilibrium best responses that are very different from those predicted by the standard RASNE model. To this extent, these models can explain a wider range of outcomes than the RASNE model, but at the cost of analyzing behavior in the aggregate rather than at the individual level. We propose to check the RASNE model by identifying and estimating a structural model that does not cast this particular common knowledge assumption so that we can assess it without aggregating individual data.

To account for the observed heterogeneity in the overbidding, Cox, Roberson and Smith 
(1982) and Cox, Smith and Walker $(1982,1983,1985,1988)$ developed a Nash equilibrium model that assumes heterogeneous constant relative risk attitudes (henceforth the CRRA model). To the difference of the RASNE model which assumes that bidders' preferences are all characterized by the same risk parameter, the CRRA model assumes the individual risk parameters to be drawn from a given distribution, which is assumed common knowledge. Cox et al. (1988) and Cox and Oaxaca (1996) estimate individual bid functions and conclude that the CRRA model outperforms the RASNE model in explaining the data. Chen and Plott (1998) report similar evidence from first-price auction experiments in which bidders draw their valuations from non-uniform distributions. They also estimate CRRA bid functions without imposing restrictions on the parameters of the distribution of risk preferences and find that such bid functions fit the data better than the CRRA bid functions, which are estimated with restrictions. ${ }^{2}$ Rather then estimating reduced-form individual bid functions, our approach consists in $i$ ) checking whether bidders display a homogenous behavior or not, ii) constructing a structural test for the CRRA model for $n$ bidders with uniformly distributed valuations and iii) assessing the model on a "Accept / Reject" basis.

We assess the RASNE and CRRA models with samples of data from Cox, Roberson and Smith (1982), Cox et al. (1988) and Isaac and Walker (1985). The data we use refer to 32 auction sessions with 3, 4 and 5 bidders and constitute a total of 2320 observations. Our main results can be summarized in three points.

First, we find that the RASNE model is supported by the data of Cox, Roberson and Smith (1982) on auctions with 3, 4 and 5 bidders but not by those of Cox et al. (1988) neither those of Isaac and Walker (1985) on auctions with 3 and 4 bidders that were collected with a more common experimental procedure. This result suggests that the experimental procedure used by Cox, Roberson

\footnotetext{
${ }^{2}$ Chen and Plott (1998) assume a priori that the distribution of risk parameters is a Log Normal defined on $[0, \infty)$ with mean $\mu$ and variance $\sigma^{2}$. The restrictions they impose to estimate individual CRRA bid functions are that $\mu$ and $\sigma^{2}$ are equal to the average and variance of the estimated individual risk parameters.
} 
and Smith (1982) to collect the data may have interfered with the outcomes. We also report some evidence (i.e., only 2 sessions out of 32) of a homogenous behavior that is not consistent with the RASNE model in auctions with 3 and 4 bidders. When compared to the predictions of the RASNE model, this misbehavior is characterized by an overbidding that is less than proportional at high valuations.

Second, the CRRA model is supported by the data of Cox et al. (1988) on auctions with 3 bidders but not by those of Isaac and Walker (1985) on auctions with 4 bidders, which represent the bulk of the data we examine. Our analysis therefore indicates that the benchmark CRRA model for auctions with 4 bidders does not consistently explain the observed behavior, mostly because of the presence of non-linearities in the estimated bid functions that do not conform to the theoretical predictions.

Third, our analysis shows the possible drawbacks of overlooking the homogeneity hypothesis when testing symmetric auction models. If we cannot test this hypothesis (e.g., because we do not have the relevant data), then we would analyze behavior in the aggregate and we would not reject the Nash model for homogeneous constant relative risk attitudes (at $\alpha=.70$, one-tailed). If, in addition, we assume that we only know that the support of the distribution of valuations is the unit interval, then we would not be able to reject the Nash model for risk neutral bidders and we would erroneously conclude that the estimated distributions of valuations are mostly non-Uniform. As in both cases the prior testing of the homogeneity hypothesis would change our inferences for some treatments, our study puts in perspective the sensitivity of structural inferences to the available information.

In the next section we present the theoretical framework to analyze first-price auction data from experiments with uniformly drawn valuations. In Section 3, we review the data we use to assess the RASNE and CRRA models of bidding and we outline the test procedures. Section 4 reports the 
outcomes and Section 5 concludes.

\section{Theoretical framework}

We consider a first-price sealed-bid auction game in which $n$ bidders compete for the purchase of a single object. This object is awarded to the highest bidder for a price equal to her/his bid. Each bidder receives a private valuation $v_{i}$ for the object before the auction starts. These valuations are independent draws (with replacement) from a distribution $F_{0}$ which is defined on $I=[\underline{v} ; \bar{v}]$ and which belongs to a parametric family of distributions $F_{\theta}$ with $\theta \in \Theta \subseteq \mathbb{R}^{k}$ and $F_{0}=F_{\theta^{0}}$ for some $\theta^{0} \in \Theta$. Bidders are assumed to have the same utility function $u($.$) on monetary payments, with$ $u^{\prime}>0, u^{\prime \prime} \leq 0$ and $u(0)=0$. The parameters $n, F_{0}, I$ and the utility function $u($.$) are assumed$ common knowledge. If bidder $i$ has a valuation $v_{i}$, her/his utility of winning the auction with a bid $b_{i}$ is given by $u\left(v_{i}-b_{i}\right)$. The expected utility of bidder $i$ can thus be defined as

$$
U\left(v_{i}, b_{i}\right)=u\left(v_{i}-b_{i}\right) P\left[b_{i}>\max _{j \neq i}\left\{b_{j}\right\}\right]
$$

where $P[$.$] stands for the buyer's probability of winning with a bid equal to b_{i}$. A bidding strategy $b($.$) is a symmetric Nash equilibrium strategy if for all valuations, it is a best response for bidder i$ to use $b($.$) if all bidders j \neq i$ also use $b($.$) . Maskin and Riley (2000) show that in such a context, if$ $b($.$) is a best response then it is monotone increasing in bidders' valuations. Therefore, if b^{-1}\left(b_{i}\right)$ stands for the inverse of $b($.$) then bidder i$ 's expected payoff is defined as

$$
\begin{aligned}
U\left(v_{i}, b_{i}\right) & =u\left(v_{i}-b_{i}\right) P\left[v_{j}<b^{-1}\left(b_{i}\right), \forall j \neq i \mid v_{i}\right] \\
& =u\left(v_{i}-b_{i}\right)\left[F_{\theta^{0}}\left(b^{-1}\left(b_{i}\right)\right)\right]^{n-1}
\end{aligned}
$$

The first order condition to maximize $U\left(v_{i}, b_{i}\right)$ is given by 


$$
\begin{aligned}
\partial_{b_{i}} U\left(v_{i}, b_{i}\right)=- & u^{\prime}\left(v_{i}-b_{i}\right)\left[F_{\theta^{0}}\left(b^{-1}\left(b_{i}\right)\right)\right]^{n-1} \\
& +u\left(v_{i}-b_{i}\right) \frac{(n-1)\left[F_{\theta^{0}}\left(b^{-1}\left(b_{i}\right)\right)\right]^{n-2} f_{\theta^{0}}\left(b^{-1}\left(b_{i}\right)\right)}{b^{\prime}\left(b^{-1}\left(b_{i}\right)\right)}=0
\end{aligned}
$$

Imposing the Nash requirement and assuming a symmetric behavior, we have $b_{i}=b\left(v_{i}\right)$. Substituting $b_{i}=b\left(v_{i}\right)$ into (1) yields the following nonlinear first order differential equation

$$
b^{\prime}\left(v_{i}\right)=\frac{d \ln \left[F_{\theta^{0}}\left(v_{i}\right)\right]^{n-1}}{d \ln u\left(v_{i}-b\left(v_{i}\right)\right)} \quad \text { with } b(0)=0
$$

This equation indicates that, in equilibrium, the slope of the bid function must be equal to the elasticity of substitution between the probability of winning and bidder $i$ 's payoff. As risk neutrality is characterized by $u(w)=w$, overbidding may be explained in terms of risk aversion since by concavity we have $d \ln u(w)<d \ln w, \forall \mathrm{w}>0$; the slope of the bid function in (2) is greater under risk aversion than under risk neutrality. Following Holt (1980) and Cox, Smith and Walker (1982), we assume bidders to display homogeneous constant relative risk averse preferences so that $u(w)=w^{r}$ for $i=1, \ldots, n$ and where $1-r \neq 0$ represents the buyers' common Arrow-Pratt index of constant relative risk aversion. With such preferences, (2) yields the following RASNE bid function

$$
b_{i}=\varphi_{i}\left(\theta^{0}, v_{i}, r\right)=v_{i}-\int_{\underline{v}}^{v_{i}}\left[\frac{F_{\theta^{0}}(s)}{F_{\theta^{0}}\left(v_{i}\right)}\right]^{\frac{n-1}{r}} d s
$$

If $r=1$ then the model reverts to Vickrey's benchmark model that has been tested with field data by Laffont, Ossard and Vuong (1995).

To determine a closed-form estimable data generating process, we need to specify the distribution of valuations $F_{0}$. One possible specification would be to use the available information about the subjects' common distribution of valuations so that the estimation of (3) would boil down to the estimation of the risk parameter $r$. However, if valuations are drawn from a Uniform 
distribution on $[\underline{v} ; \bar{v}]$, as it is the case in most auction experiments, then (3) yields linear RASNE bid functions. To this extent, such a specification would generate a one-parameter model that imposes $a$ priori a linearity condition on the bid functions to be estimated. We propose instead to test this condition by using the fact that the Uniform distribution on $[0 ; 1]$ is a member of the Beta family of distributions $B_{\theta}(.) \equiv B\left(\theta_{1}, \theta_{2}\right)$ which assumes $\theta_{1}=\theta_{2}=1$. We motivate such a specification by the flexible functional form of the Beta distribution, which can fit a wide variety of empirical distributions defined on the unit interval, including asymmetric uni- and bi-modal ones (at 0 and 1 ).

Thus, if we consider a sample of $t=1, \ldots, T$ repetitions of first-price auctions with $n$ bidders who have their values drawn (with replacement) from a Uniform distribution on $[\underline{v} ; \bar{v}]$, then by normalizing bids and values to the $[0 ; 1]$ interval, the data generating process (3) would take the following expression

$$
b_{i t}=\varphi_{i t}\left(\theta^{0}, v_{i t}, r\right)=v_{i t}-\int_{0}^{v_{i t}}\left[\frac{B_{\theta^{0}}(s)}{B_{\theta^{0}}\left(v_{i t}\right)}\right]^{\frac{n-1}{r}} d s+w_{i t}
$$

where $w_{i t}$ stands for a non-systematic error term with $E\left(w_{i t} \mid v_{i t}\right)=0$ to account for bidders' possible trial-and-error behavior. If $\theta^{0}$ is set equal to $(1,1)$ then the only parameter of interest to be estimated would be the risk averse parameter $r$. Equation (4) can also be seen as an estimating equation where both $r$ and $\theta^{0}$ are unknown. In this framework, if individuals do not act as predicted by the RASNE model, the estimates of $\theta^{0}$ should be significantly different from $(1,1)$. However, if we were to estimate these parameters with (4), we would face a problem of identification because there is no one-to-one mapping from the sampling space to the parameter space. ${ }^{3}$ The following proposition shows that this is indeed the case

\footnotetext{
${ }^{3}$ The non-identification of structural models of first-price auctions with independent private values and risk averse bidders has been shown to hold in the generality by Campo, Guerre, Perrigne and Vuong (2000) in independent research.
} 
Proposition 1: $\forall r \neq 1$, there exists $\theta^{*}=\left(\theta_{1}^{*}, \theta_{2}^{*}\right)$ such that:

$$
\varphi((1,1), v, r)=\varphi\left(\left(\theta_{1}^{*}, \theta_{2}^{*}\right), v, 1\right), \forall v \in[\underline{v}, \bar{v}]
$$

This holds only for $\theta_{1}^{*}=1 / r$ and $\theta_{2}^{*}=1$.

Proof: See Appendix 1.

Proposition 1 states that if bidders are risk averse and act in the Nash equilibrium, the evidence would be indistinguishable from a Nash equilibrium model that assumes risk neutrality and valuations drawn from non-uniform distributions. It also provides conditions on the parameters $\theta_{1}, \theta_{2}$ and $r$ so that the RASNE model can be tested. These conditions are that if we cannot reject the null that $\theta_{2}=1$ then $r=1 / \theta_{1}$ and the estimated bid function is linear in valuations with a slope equal to $(n-1) /\left(n-1+\frac{1}{\theta_{1}}\right)$, as predicted by the RASNE model for uniformly drawn valuations. In this framework, non-linear bid functions are characterized by $\theta_{2} \neq 1$ and are interpreted as evidence against the RASNE model. From Proposition 1, it appears that a particularly useful restriction to impose on the estimation of (4) is $r=1$, in which case the estimation procedure would simplify to the one of

$$
b_{i t}=\varphi_{i t}\left(\theta^{0}, v_{i t}, 1\right)=v_{i t}-\int_{0}^{v_{i t}}\left[\frac{B_{\theta^{0}}(s)}{B_{\theta^{0}}\left(v_{i t}\right)}\right]^{n-1} d s+w_{i t}
$$

This restriction ensures identification of the $\theta$ parameter and implies that if the RASNE model holds, then it must be that $\theta_{1}$ and $\theta_{2}$ should not be significantly different from $1 / r$ and 1 , respectively. Therefore, we can assess the RASNE model of bidding by testing the following null hypothesis in implicit form 


$$
\begin{aligned}
& H_{0}:\left(\begin{array}{l}
\theta_{1}^{0} \\
\theta_{2}^{0}
\end{array}\right)=\left(\begin{array}{c}
1 / r_{0} \\
1
\end{array}\right) \\
& H_{1}:\left(\begin{array}{c}
\theta_{1}^{0} \\
\theta_{2}^{0}
\end{array}\right) \neq\left(\begin{array}{c}
1 / r_{0} \\
1
\end{array}\right)
\end{aligned}
$$

The null hypothesis in equation (5) defines a function $h: \mathbb{R} \rightarrow \mathbb{R}^{2}$ such that if the RASNE model holds and $r_{0}$ is the true constant relative risk aversion parameter, then there is an implicit restriction on the parameter space of $\theta$ which is given by $\theta^{0}=h\left(r_{0}\right)$. To test this implicit restriction, we consider the distance between a consistent estimate of $\theta^{0}$ under both the null and the alternative hypotheses, $\hat{\theta}$, and $\hat{\theta}^{0}$, which is consistent only under the null, and we test whether this distance is statistically significant. A consistent estimator under the null hypothesis is given by $\hat{\theta}^{0}=h(\hat{r})$, where $\hat{r}$ is a consistent estimate of the true risk aversion parameter $r_{0}$. This consistent estimator can be found by estimating the linear model $b_{i t}=\gamma v_{i t}+\varepsilon_{i t}$ by OLS, in which case $\hat{r}=(n-1)(1-\hat{\gamma}) / \hat{\gamma}$. As for $\hat{\theta}$, a consistent estimator can be found by Non Linear Least Squares (NLLS) estimation, i.e.,

$$
\hat{\theta}=\underset{\theta}{\operatorname{ArgMin}}: S_{n T}(\theta) \equiv \sum_{i=1}^{n} \sum_{t=1}^{T}\left(b_{i t}-\varphi_{i t}(\theta)\right)^{2}
$$

which is an asymptotically normal estimator so that $\sqrt{n T}\left(\hat{\theta}-\theta^{0}\right) \rightarrow N\left(0, J_{0}^{-1} I_{0} J_{0}^{-1}\right)$, where $I_{0}$ is the information matrix, and where $J_{0}$ stands for the asymptotic Hessian of (5').

Following Gourieroux and Monfort (1995), it can be shown that $\sqrt{n T}\left(\hat{\theta}-\hat{\theta}^{0}\right)$ is asymptotically normal with a variance-covariance matrix given by $V=M_{h} J_{0}^{-1} I_{0} J_{0}^{-1} M_{h}^{\prime}$, where $M_{h}$ is the orthogonal projection of $h_{r_{0}}=\partial_{r} h\left(r_{0}\right)$ on the space spanned by the columns of $\boldsymbol{J}_{0}$. Notice that since the only effective restriction in (5) is the one affecting $\theta_{2}^{0}$, the $2 \times 2$ matrix $V$ is singular. Therefore, an asymptotic test of (5) at the required confidence level can be computed as

$$
n T\left(\hat{\theta}-\hat{\theta}^{0}\right)^{\prime} V^{+}\left(\hat{\theta}-\hat{\theta}^{0}\right) \rightarrow \chi_{k-q}^{2}
$$


where $V^{+}$denotes the generalized inverse. If the variance-covariance matrix $\Omega$ of the nonsystematic error term $w_{i t}$ is assumed to be a scalar matrix, $V^{+}$can be consistently estimated using the outer product of the gradients $\sum_{i} \sum_{t} \partial_{\theta} \varphi_{i t}(\theta) \partial_{\theta} \varphi_{i t}(\theta)^{\prime}$. In general, however, one would expect some degree of both heteroskedasticity and autocorrelation in the error term. One the one hand, as bidding above ones valuation is a seldom event in first-price auction experiments, we can expect that bids will be less dispersed at low valuations than at high valuations. On the other hand, even though valuations are independently and identically sampled, errors in bids could be autocorrelated because of bidders' possible trial-and-error behavior. Therefore, given the possible presence of heteroskedasticity and autocorrelation of unknown forms, we use a Newey-West estimator, $\hat{I}$, of the information matrix $I_{0}$. Using $\hat{J}=\frac{2}{n} \Psi(\hat{\theta}) \Psi(\hat{\theta})^{\prime}$ as a consistent estimator of the asymptotic Hessian of (5'), the test of the RASNE model is then computed as

$$
n T\left(\hat{\theta}-\hat{\theta}_{0}\right)^{\prime}\left(M_{h} \hat{J}^{-1} \hat{I} \hat{J}^{-1} M_{h}^{\prime}\right)^{+}\left(\hat{\theta}-\hat{\theta}^{0}\right) \rightarrow \chi_{k-q}^{2}
$$

To simplify the computation of (6), we proceed with a re-parametrization of the model. As the parametric space in our model reduces to the positive orthant of the real plane, we will solve (5') in the logarithm of the parameters rather than in the parameters themselves. Hence, if $\tilde{\theta}$ stands for the log-parameters, then $h\left(\tilde{\theta}_{1}, \tilde{\theta}_{2}\right)=(\ln (1 / r), 0)$ and $\partial_{r} h=(-1 / r, 0)$. Replacing in (6), it can then be shown that the chi-squared test reduces to a normal test.

Proposition 2: Under the null hypothesis in (5), the t-statistic $t=\frac{\hat{\tilde{\theta}}_{2}}{\hat{\sigma}_{\hat{\theta}_{2}}}$ is asymptotically normal with zero mean and unit standard deviation.

Proof: See Appendix 1. 
Proposition 2 states that a test of the RASNE model when valuations are uniformly drawn reduces to a standard normal test of the significance of the second log-parameter $\tilde{\theta}_{2}$ of the estimated Beta distribution.

Clearly, the above model of bidding assumes symmetric bidders with homogenous constant relative risk averse preferences. In what follows, we use two properties of the model proposed by Cox, Roberson and Smith (1982) and Cox et al. (1988) for heterogeneous constant relative risk averse bidders to construct a structural test. The CRRA model assumes that bidders' utilities of winning are characterized by $u_{i}(w)=w^{r_{i}}$, where $r_{i}$ is i.i.d. according to a distribution $G($.$) which$ has a positive continuous density function $g($.$) on \left(0, r_{\max }\right]$, with $r_{\max }$ standing for the risk parameter of the least risk averse bidder. As first-price auction experiments usually report a significant overbidding, risk neutrality appears as a "natural" lower bound on bidders' risk aversion so that in what follows we shall assume $r_{\max }=1$. A first property of this model is that if bidders' valuations are uniformly distributed, then the individual equilibrium strategies are linear up to the maximum possible bid, $b^{*}$, of the least risk averse bidder and they have no closed-form solution for bids greater than $b^{*}$. For uniformly drawn valuations on the unit interval, $b^{*}=(n-1) /\left(n-1+r_{\max }\right)$--- see Cox et al. (1988). ${ }^{4}$ The second property is that if valuations are uniformly distributed then, for a given $r_{\max }$, the distribution $G($.$) does not affect the linear part of$ the equilibrium bidding strategies.

A structural test of the CRRA model would thus consist in checking first that the bidders participating in a given session do not display a homogenous bidding behavior, then whether their

\footnotetext{
${ }^{4}$ For a numerical derivation of the CRRA bid functions with uniformly distributed valuations and various distributions of risk aversion parameters, see Van Boening, Rassenti and Smith (1998). Notice that for a given number of bidders, $b^{*}$ is inversely related to $r_{\max }$, so that the estimation of linear bidding strategies would refer to less observations as $r_{\max }$ increases. We can therefore conjecture that, given $n$, the larger $r_{\max }$ and the less likely we would be able to reject the null that the estimated bid functions are linear for bids smaller than $b^{*}$.
} 
bid functions are linear in valuations for bids smaller than $b^{*}$, and finally whether the estimated risk aversion parameters of a given session are all smaller or equal to 1 . The testing of the last two items (i.e., the linearity of bid functions for bids smaller than $b^{*}$ and $r_{i} \leq 1, \forall i$ ) hinges upon the type of non-linearity in the estimated bid functions.

On the one hand, if we cannot reject the linearity hypothesis (which is implied by $\theta_{2 i}^{0}=1$ for $i=1, \ldots, n)$, then we only need to correct our initial estimates of $\theta_{1 i}^{0}$ and $\theta_{2 i}^{0}$ by removing all realizations of valuations (and their corresponding bids) that would lead a bidder with $r_{i}$ to bid more than $b^{*}$, assuming that she/he plays in equilibrium. We do so by using an iterative procedure proposed by Walker, Smith and Cox (1990, note 3) which consists in estimating, for each session that did not reject the linearity hypothesis, the individual risk parameters $r_{i}=1 / \theta_{1 i}$ and to use these estimates to determine, for each bidder $i$, the valuation $v_{i}^{*}$ corresponding to $b^{*}$. The iterative procedure then consists in removing all observations $v_{i t}>v_{i}^{*}$ and their corresponding bids, and in re-estimating the model to obtain new $r_{i}$ estimates and new $v_{i}^{*}$ values. This procedure is repeated until no more observations can be deleted from the dataset. At each iteration of the procedure, we checked that the $\theta_{2 i}^{0}$ estimates are still all equal to 1 after deleting $v_{i t}>v_{i}^{*}$. The final parameter estimates $\hat{\theta}_{1 i^{*}}$ and $\hat{\theta}_{2 i^{*}}$ are then used to test the null hypotheses that $\theta_{1 i^{*}}^{0} \geq 1$ and that $\theta_{2 i^{*}}^{0}=1$ for $i=1, \ldots, n$.

On the other hand, if we reject the linearity hypothesis then the iterative deletion of valuations $v_{i}>v_{i}^{*}$ could mislead our inferences. This is because for those bidders who display nonlinear bid functions, the initial estimates of the risk parameters would be biased. We therefore estimate (4') by restricting the $\theta_{2 i}$ parameters that are significantly different from 1 to be equal to 1 , and we launch the iterative procedure using the $\theta_{1 i}$ parameters estimated under this restriction. Once 
we removed all the undesirable realizations of valuations (and the corresponding bids) from the dataset, we estimate (4') without any restriction and test the null hypotheses that that $\theta_{1 i^{*}}^{0} \geq 1$ and that $\theta_{2 i^{*}}^{0}=1$ for $i=1, \ldots, n$.

\section{Data and Testing Procedures}

We test the RASNE and the CRRA models with samples of data from Cox, Roberson and Smith (1982), Cox et al. (1988) and Isaac and Walker (1985). ${ }^{5}$ The experiments consisted of independent private value first-price auction sessions with uniformly drawn valuations and human bidders. The sessions that we selected vary in terms of the number of participating bidders, the number of rounds played, the experimental procedure used, the bidders' experience of the game and/or whether payoffs were tripled or not.

The data were collected with two different experimental procedures or designs. In Cox et al. (1982), bidders play in blocks of 10 auction rounds and know in round 1 the valuations that they will have in each of the 10 following rounds. We henceforth refer to this design as Design A. In Cox et al. (1988) and Isaac and Walker (1985), bidders received their valuations at the outset of each round they played. We henceforth refer to this design as Design B. Experienced bidders are bidders who already participated in a first-price auction experiment. Sessions in which payoffs were tripled were conducted to check if behavior is affected by multiplied payoffs, which should not be the case according to the CRRA model of bidding. Further details on these experimental designs are reported in Cox et al. (1988).

We discarded from the analysis the few sessions that involve experienced subjects who were recruited on the basis of their performance in previous experiments because the outcomes of these

\footnotetext{
${ }^{5}$ Some of these samples were also used by Harrison (1990) and by Cox and Oaxaca (1996). Much of the debate over Harrison's (1989) flat maximum critique also referred to these data samples --- see Cox, Smith and Walker (1992), Friedman (1992), Harrison (1992) and Kagel and Roth (1992).
} 
sessions could bias our inferences. ${ }^{6}$ We also discarded the few sessions with 6 and 9 bidders and those for which the equilibrium bidding strategies have to be re-defined because bidders' payoffs were transformed. We discarded all these sessions mostly because they represented too few independent observations to draw our statistical inferences --- the statistical test we use to assess the models is explained below. The data we use represent a total of 2320 observations, spread over 32 sessions and their main characteristics are summarized in Table 1.

Table 1: Data Characteristics

\begin{tabular}{|l|c|c|c|c|c|c|c|c|}
\hline \multicolumn{1}{|c|}{ Sessions } & Paper $^{\mathrm{a}}$ & $\begin{array}{c}\text { \#bidders } / \\
\text { session } \\
(n)\end{array}$ & $\begin{array}{c}\text { \#rounds } / \\
\text { session } \\
(T)\end{array}$ & $\begin{array}{c}\text { Total } \\
\text { \# obs }\end{array}$ & {$[\underline{v}, \bar{v}]$} & Design & $\begin{array}{c}\text { Experi- } \\
\text { ence }\end{array}$ & $\begin{array}{c}\text { Payoff } \\
\text { Multiple }\end{array}$ \\
\hline dfd3; dfd10' & CRS & 3 & 10 & 60 & $0.1 ; 4.9$ & A & No & 1 \\
fdf10; fdf3' & CRS & 3 & 20 & 120 & $0.1 ; 4.9$ & A & No & 1 \\
fpn3(1); fpn3(2) & CSW & 3 & 20 & 120 & $0 ; 6$ & B & No & 1 \\
dfd10x & CRS & 3 & 10 & 30 & $0.1 ; 4.9$ & A & Yes & 1 \\
fpn3(1)x,..fpn3(3)x & CSW & 3 & 20 & 180 & $0 ; 6$ & B & Yes & 1 \\
\hline dfd8' & CRS & 4 & 10 & 40 & $0.1 ; 8.1$ & A & No & 1 \\
fdf8 & CRS & 4 & 20 & 80 & $0.1 ; 8.1$ & A & No & 1 \\
dfd8x & CRS & 4 & 10 & 40 & $0.1 ; 8.1$ & A & Yes & 1 \\
dfd8x* & CRS & 4 & 10 & 40 & $0.1 ; 8.1$ & A & Yes & 3 \\
fdf8'x & CRS & 4 & 20 & 80 & $0.1 ; 8.1$ & A & Yes & 1 \\
fdf8'x* & CRS & 4 & 20 & 80 & $0.1 ; 8.1$ & A & Yes & 3 \\
fp1onci(1),..,,(10) & IW & 4 & 25 & 1000 & $0 ; 10$ & B & No & 1 \\
\hline dfd9 & CRS & 5 & 10 & 50 & $0.1 ; 12.1$ & A & No & 1 \\
dfd9* & CRS & 5 & 10 & 50 & $0.1 ; 12.1$ & A & No & 3 \\
fdf9' & CRS & 5 & 20 & 100 & $0.1 ; 12.1$ & A & No & 1 \\
fdf9' & CRS & 5 & 20 & 100 & $0.1 ; 12.1$ & A & No & 3 \\
dfd9'x & CRS & 5 & 10 & 50 & $0.1 ; 12.1$ & A & Yes & 1 \\
fdf9x & CRS & 5 & 20 & 100 & $0.1 ; 12.1$ & A & Yes & 1 \\
\hline
\end{tabular}

Note: ${ }^{a}$ CRS: Cox, Roberson and Smith (1982); CSW: Cox, Smith and Walker (1988); IW: Isaac and Walker (1985). CRS sessions with 3 bidders are labelled as series 1(3) in Cox et al. (1988, Tables 1 \& 2); CSW sessions as 1'(3); CRS sessions with 4 bidders and no-tripled payoff as 2(4); with tripled payoffs as 3(4); IW sessions as 4(4); CRS sessions with 5 bidders and no-tripled payoffs as 5(5); with tripled payoffs as 6(5).

Our estimation results refer to the use of Non Linear Least Squares methods and we consider a test result to be significant if we reject the null hypothesis at $\alpha=.10$, two-tailed. We summarize the

\footnotetext{
${ }^{6}$ Subjects in these treatments were recruited if their estimated linear bid functions had no significant intercept term, if their estimated constant relative risk aversion parameters lied in the $(0,1]$ interval and if the correlation coefficient between their values and bids exceeded .90 --- Walker, Smith and Cox (1990, p.15). The data of these treatments were also analyzed in Cox et al. (1985).
} 
testing procedures as follows. We start by normalizing the bid and value data of each session in the $[0,1]$ interval. $^{7}$ We then check, for each session, if bidders display a homogenous behavior by estimating (4') with individual dummy variables for the parameters $\theta_{1}$ and $\theta_{2}$ and by checking for significant differences in their estimates across bidders. More precisely, we define the individual dummy variables $\delta_{\cdot j}$ so that

$$
\begin{aligned}
& \theta_{1 i}=\theta_{11}+\sum_{j=2}^{n} \delta_{1 j} \mathbf{1}_{\{i=j\}} \\
& \theta_{2 i}=\theta_{21}+\sum_{j=2}^{n} \delta_{2 j} \mathbf{1}_{\{i=j\}}
\end{aligned} \quad \text { with } i=1, \ldots, n
$$

and we check the significance of the $\delta_{. j}$ parameters. We henceforth refer to the null hypothesis of this test as $H_{0}^{0}$. If we cannot reject homogeneity, we estimate $\theta_{1}$ and $\theta_{2}$ in (4') without individual dummy variables to assess the RASNE model. We test this hypothesis by testing if $\theta_{2}^{0}$ equals 1 $\left(H_{0}^{1 \beta}\right.$ ). If we cannot reject $H_{0}^{1 \beta}$, we also test whether bidders' behavior is significantly different from the Risk Neutral Nash Equilibrium (RNNE) behavior by testing if $\theta_{1}^{0}$ is equal to $1\left(H_{0}^{1 \alpha}\right)$.

If we reject the homogeneity hypothesis for a given session, then we check for linearity in the estimated bid functions by testing whether all $\theta_{2 i}^{0}$ parameters are equal to 1 . We refer to the null hypothesis of this test as $H_{0}^{2 \beta}$. We then use the iterative procedure described in the previous section to estimate the parameters $\theta_{1 i^{*}}^{0}$ and $\theta_{2 i^{*}}^{0}$ and test the null hypotheses that all bid functions of a given session are linear for bids smaller or equal to $b^{*}\left(H_{0}^{2 \beta^{*}}\right)$ and if so, that the $n$ risk parameters of that session are smaller or equal to $1\left(H_{0}^{2 \alpha^{*}}\right)$. If neither of these hypotheses can be rejected, then we would not reject the CRRA model of bidding as a possible explanation for the observed behavior.

\footnotetext{
${ }^{7}$ As valuations were drawn from a Uniform distribution on $[\underline{v} ; \bar{v}]$, we normalized both valuations $\mathrm{v}_{i t}$ and bids $\mathrm{b}_{i t}$ as $v_{i t}=\left(\mathrm{v}_{i t}-\underline{v}\right) /(\bar{v}-\underline{v})$ and $b_{i t}=\left(\mathrm{b}_{i t}-\underline{v}\right) /(\bar{v}-\underline{v})$, respectively.
} 
Finally, we assume that any test outcome for a given session is a Binomial variable that takes the value 1 if the null hypothesis $\mathcal{H}_{0}$ of this test cannot be rejected (at $\alpha=.10$, two-tailed) and 0 otherwise. We then run a one-tailed Binomial test on the number of non-rejections given the total number of times $\mathcal{H}_{0}$ has been tested and given a probability of success of .5. The null hypothesis of this test is that $\mathcal{H}_{0}$ is equally likely to be rejected and the alternative is that $\mathcal{H}_{0}$ is more likely to be rejected than not. For a given number of non-rejections, we report the probability to observe as many non-rejections or less given that $\mathcal{H}_{0}$ is true, and we take for significance level a one-tailed $\alpha=.10$.

We use this non-parametric test because it allows a straightforward assessment of a given hypothesis by only requiring that observations (i.e., the "Accept / Reject" test outcomes) are independent realizations of a Binomial variable.

\section{Estimation Results}

We concentrate our discussion on the outcomes of the Binomial test that are reported in Table 2. We report the NLLS estimation results for auction sessions with 3, 4 and 5 bidders in Appendix 2 of the paper, and we occasionally refer to them. (As we could not reject the null hypothesis $H_{0}^{2 \alpha^{*}}$ that $r_{i} \leq 1$ for bidders who display a linear bid function on $\left[0, b^{*}\right]$, the tables in Appendix 2 do not report the outcomes of this test.)

\subsection{Homogenous behavior}

We first analyze the outcomes of sessions with inexperienced bidders and no tripled payoffs. The summary statistics in the upper panel of Table 2 indicate that we reject the homogeneity hypothesis ( $H_{0}^{0}$ ) for auctions with 4 bidders but not for auctions with 3 bidders. The same holds for the RASNE 
model of bidding. The test outcomes on the $\theta_{l}$ estimates $\left(H_{0}^{1 \alpha}\right)$ further indicate that we cannot reject the risk neutral Nash equilibrium model for two sessions with 3 bidders (see Table I in Appendix 2).

Table 2: Frequencies of Non-Rejection and Binomial Test Outcomes

\begin{tabular}{|c|c|c|c|c|c|c|c|}
\hline & $\begin{array}{l}\text { Sessions } \\
\text { with }\end{array}$ & $\begin{array}{c}\text { Exp. } \\
\text { Design }\end{array}$ & $H_{0}^{0}$ & $\begin{array}{l}\text { RASNE } \\
H_{0}^{0}+H_{0}^{1 \beta}\end{array}$ & $\mathrm{CRRA}^{\ddagger}$ & $\begin{array}{c}\text { Total \# of } \\
\text { sessions }\end{array}$ & $r$ \\
\hline \multirow{3}{*}{$\begin{array}{c}\text { Inexperienced } \\
\text { Bidders } \\
\& \text { No Tripled } \\
\text { Payoffs }\end{array}$} & $n=3$ & $\mathrm{~A} \& \mathrm{~B}$ & $\begin{array}{c}4 \\
(.8906)\end{array}$ & $\begin{array}{c}3 \\
(.6563)\end{array}$ & $\begin{array}{c}0 \\
(.0156)\end{array}$ & 6 & $\begin{array}{c}.94 \\
\text { [n.a.] }\end{array}$ \\
\hline & $n=4$ & $\mathrm{~A} \& \mathrm{~B}$ & $\begin{array}{c}3 \\
(.0730)\end{array}$ & $\begin{array}{c}2 \\
(.0193)\end{array}$ & $\begin{array}{c}3 \\
(.0730)\end{array}$ & 12 & $\begin{array}{c}.40 \\
{[.51]}\end{array}$ \\
\hline & $n=5$ & A & $\begin{array}{c}0 \\
\text { (n.a.) }\end{array}$ & $\begin{array}{c}0 \\
\text { (n.a.) }\end{array}$ & $\begin{array}{c}1 \\
\text { (n.a.) }\end{array}$ & 2 & $\begin{array}{l}\text { n.a. } \\
{[.47]}\end{array}$ \\
\hline \multirow{3}{*}{ Pooled Data } & $n=3$ & $A \& B$ & $\begin{array}{c}4 \\
(3770)\end{array}$ & $\begin{array}{c}3 \\
(1719)\end{array}$ & $\begin{array}{c}2 \\
(0547)\end{array}$ & 10 & $\begin{array}{c}.94 \\
{[.75]}\end{array}$ \\
\hline & $n=4$ & $\mathrm{~A} \& \mathrm{~B}$ & $\begin{array}{c}4 \\
(.0384)\end{array}$ & $\begin{array}{c}3 \\
(.0106)\end{array}$ & $\begin{array}{c}4 \\
(.0384)\end{array}$ & 16 & $\begin{array}{c}.41 \\
{[.49]}\end{array}$ \\
\hline & $n=5$ & A & $\begin{array}{c}1 \\
(.1094) \\
\end{array}$ & $\begin{array}{c}1 \\
(.1094) \\
\end{array}$ & $\begin{array}{c}2 \\
(.3438) \\
\end{array}$ & 6 & $\begin{array}{c}1 \\
{[.63]}\end{array}$ \\
\hline \multirow{4}{*}{$\begin{array}{l}\text { Pooled } \\
\text { by Design }\end{array}$} & \multirow[t]{2}{*}{$n=3$} & A & $\begin{array}{c}4 \\
(.9688)\end{array}$ & $\begin{array}{c}3 \\
(.8125)\end{array}$ & $\begin{array}{c}0 \\
(.0313)\end{array}$ & 5 & $\begin{array}{c}.94 \\
{[\text { n.a.] }}\end{array}$ \\
\hline & & B & $\begin{array}{c}0 \\
(.0313)\end{array}$ & $\begin{array}{c}0 \\
(.0313)\end{array}$ & $\begin{array}{c}2 \\
(.5000)\end{array}$ & 5 & $\begin{array}{l}\text { n.a. } \\
{[.47]}\end{array}$ \\
\hline & \multirow[t]{2}{*}{$n=4$} & A & $\begin{array}{c}2 \\
(.3438)\end{array}$ & $\begin{array}{c}2 \\
(.3438)\end{array}$ & $\begin{array}{c}2 \\
(.3438)\end{array}$ & 6 & $\begin{array}{c}.43 \\
{[.56]}\end{array}$ \\
\hline & & B & $\begin{array}{c}2 \\
(.0547)\end{array}$ & $\begin{array}{c}1 \\
(.0107)\end{array}$ & $\begin{array}{c}2 \\
(.0547)\end{array}$ & 10 & $\begin{array}{c}.39 \\
{[.56]}\end{array}$ \\
\hline
\end{tabular}

Note: n.a.: not applicable; Rejection probabilities in parenthesis; ${ }^{*}$ assumes a prior rejection of $H_{0}^{0}$ and no rejection of $H_{0}^{2 \beta^{*}}$ (neither of $H_{0}^{2 \alpha^{*}}$ ); ${ }^{\circ}$ average risk parameter estimate for sessions with RASNE behavior (computed from data in Tables I, II and III in Appendix 2 --- the parameter is set equal to 1 if $H_{0}^{1 \alpha}$ cannot be rejected at $\alpha=.10$, two-tailed); average risk parameter estimates for sessions that did not reject the CRRA model of bidding in brackets.

We find only two sessions in which bidders display a homogenous behavior that is not supported by the RASNE model (i.e., Session A in Table I and Session L in Table II of Appendix 2). Figure 1 reports the plots of the estimated aggregate bid functions for all sessions that did not reject the homogeneity hypothesis --- the plots refer to the parameter estimates reported in Tables I, II and 
III of Appendix 2. When compared to the estimated RASNE bid functions, the observed misbehavior is characterized by an overbidding which is less than proportional at high valuations. ${ }^{8}$

The few sessions with $n=5$ and/or with experienced and/or tripled payoffs prevents the use of the Binomial test to assess these treatment characteristics. To allow the conduct of this test, we increase the sample sizes by pooling the outcomes of sessions with inexperienced bidders with those of sessions with experienced and/or tripled payoff. ${ }^{9}$ We also pooled the outcomes of sessions with 3 and of sessions with 4 bidders. The Binomial test results for these pooled data are reported in the middle panel of Table 2. They leave our conclusions unchanged for sessions with 3 and 4 bidders. For sessions with 5 bidders, we cannot reject the null of a homogenous behavior nor the one of RNNE bidding.

We check for an experimental design effect on behavior by conducting the Binomial tests separately on sessions that were conducted with the same experimental design and the same number of bidders. The test outcomes are reported in the lower panel of Table 2. They indicate that we reject both homogeneity and the RASNE model for sessions with 3 and 4 bidders that were conducted with Design B but not for sessions with 3 and 4 (and 5) bidders that were conducted with Design A. Although there are too few independent observations to test for a significant difference in the observed behavior across designs, our results suggest that behavior is more likely to be homogenous under Design A than under Design B.

\footnotetext{
${ }^{8}$ Kagel and Roth (1992) report similar evidence from auctions with 6 and 10 bidders. In their experiments, relative bid deviations are negatively and significantly correlated to bidders' independent private valuations.

${ }^{9}$ Cox et al. (1988) report that there is no significant effect of tripling payoffs on the behavior of inexperienced bidders when $n=5$ or of experienced bidders when $n=4$ and that there is no significant difference in the behavior of inexperienced versus experienced bidders when $n=4$ or 5 .
} 
Figure 1: Estimated and Risk Neutral Nash Equilibrium Bid Functions for Sessions with Homogenous Bidders
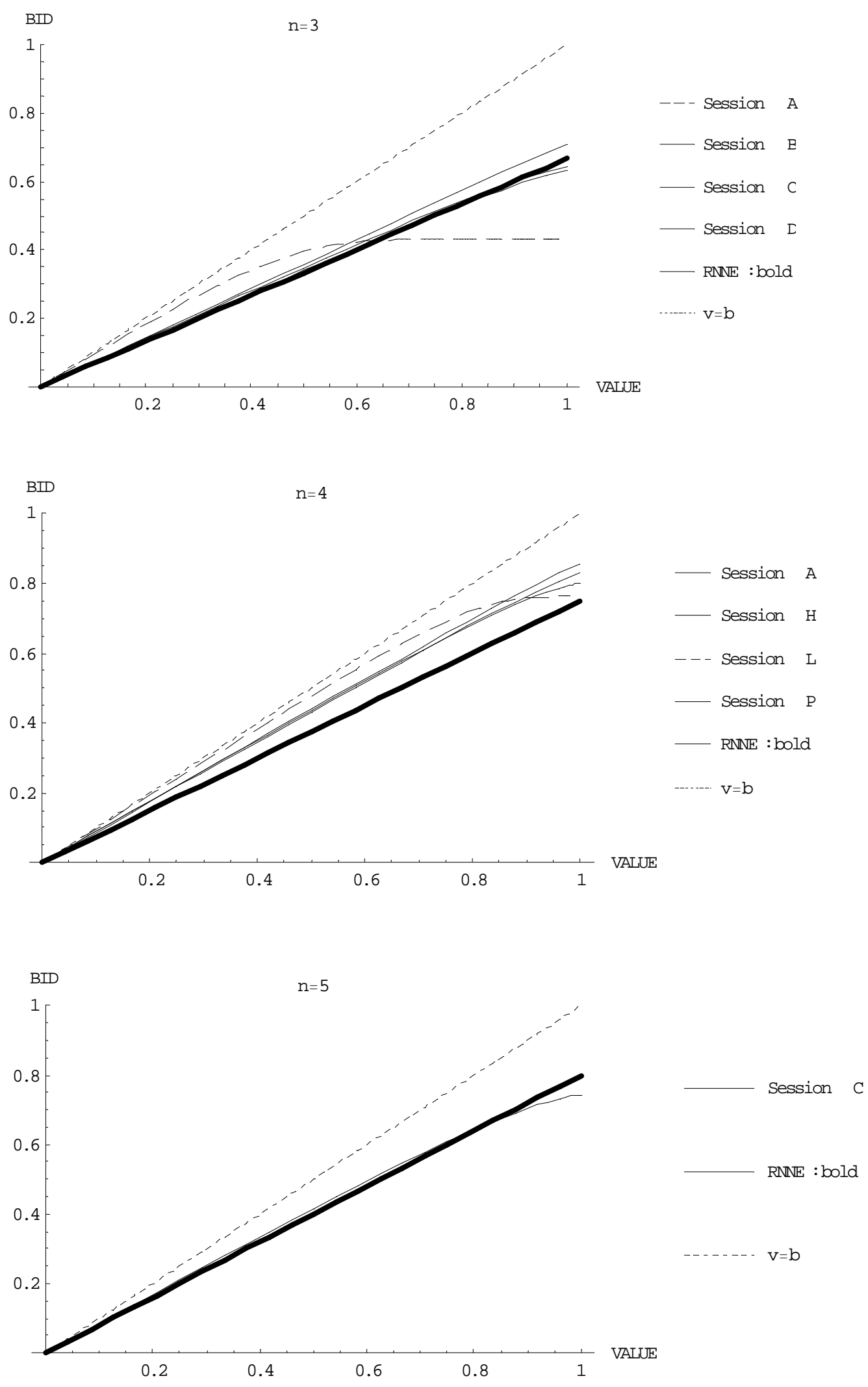


\subsection{Heterogeneous behavior}

The test outcomes reported in the upper and middle panels of Table 2 indicate that we reject the CRRA model with $r_{\max }=1$ for auctions with 3 and 4 bidders, but not for auctions with 5 bidders. The outcomes for sessions with 3 bidders are thus in line with our previous finding that we cannot reject homogeneity nor the RASNE model for these auctions. For auctions with 5 bidders, since the CRRA model is an extension of the RASNE model and since we cannot reject $H_{0}^{0}$, we only infer that we cannot reject the simplest RASNE model. More surprisingly, the rejection of both the RASNE and the CRRA models for auctions with 4 bidders indicates that behavior in these auctions is not consistent with the predictions of these models. ${ }^{10}$

When we check for an experimental design effect, we reject the CRRA model for sessions for sessions with $n=3$ that were conducted with Design A (which is line with the above findings) but not for sessions with Design B. However, this non-rejection should be kept in perspective since the Binomial test was conducted with only 5 observations. We also reject the CRRA model for sessions with 4 bidders that were conducted with Design B but not for sessions with Design A. As for the latter sessions we cannot reject the homogeneity hypothesis, we only infer that we cannot reject the simplest RASNE model.

With respect to the received literature on first-price auction experiments which finds support for the CRRA model, we explain our different results by the fact that for a given session, our approach allows us to estimate individual bid functions and to formally check for their consistency with the model's predictions. This consistency-check remains however a test in the sense that we may not reject the CRRA model even if one of the bidders displays a behavior that is significantly different from the one predicted. Such cases are shown in the plots of Figures 2(a) to 2(c) which

\footnotetext{
${ }^{10}$ Cox et al. (1992) report that for auctions with 4 bidders, only $5.7 \%$ of observations are iteratively removed from the estimation of individual CRRA bid functions. We had to remove 3\% of observations in sessions with 3 or 5 bidders and $5.25 \%$ in sessions with 4 bidders. These figures refer to sessions for which we reject $H_{0}^{0}$ but not $H_{0}^{2 \beta}$.
} 
report the estimated individual bid functions for all sessions that did not reject the CRRA model. These plots refer to the estimated coefficients of the individual dummy variables (not reported here), after applying the iterative deletion procedure. Session $\mathrm{J}$ with $n=4$ and session A with $n=5$ represent the only two cases that passed the consistency-check although one subject significantly bid below the RNNE prediction (session J), or displayed a significant nonlinear behavior (session A).

Finally, the last column of Table 2 reports the average risk parameters for the estimated RASNE and CRRA models. Although these averages are compiled from only one to three independent observations (i.e., sessions), they suggest an increase in risk aversion as the number of bidders increase from 3 to 4, which is not a pattern supported by the RASNE or CRRA model and which suggests that other factors are at play. 
Figure 2(a): Estimated Bid Functions for Sessions

with Heterogeneous CRRA Bidders --- $n=3(i=1,2,3)$
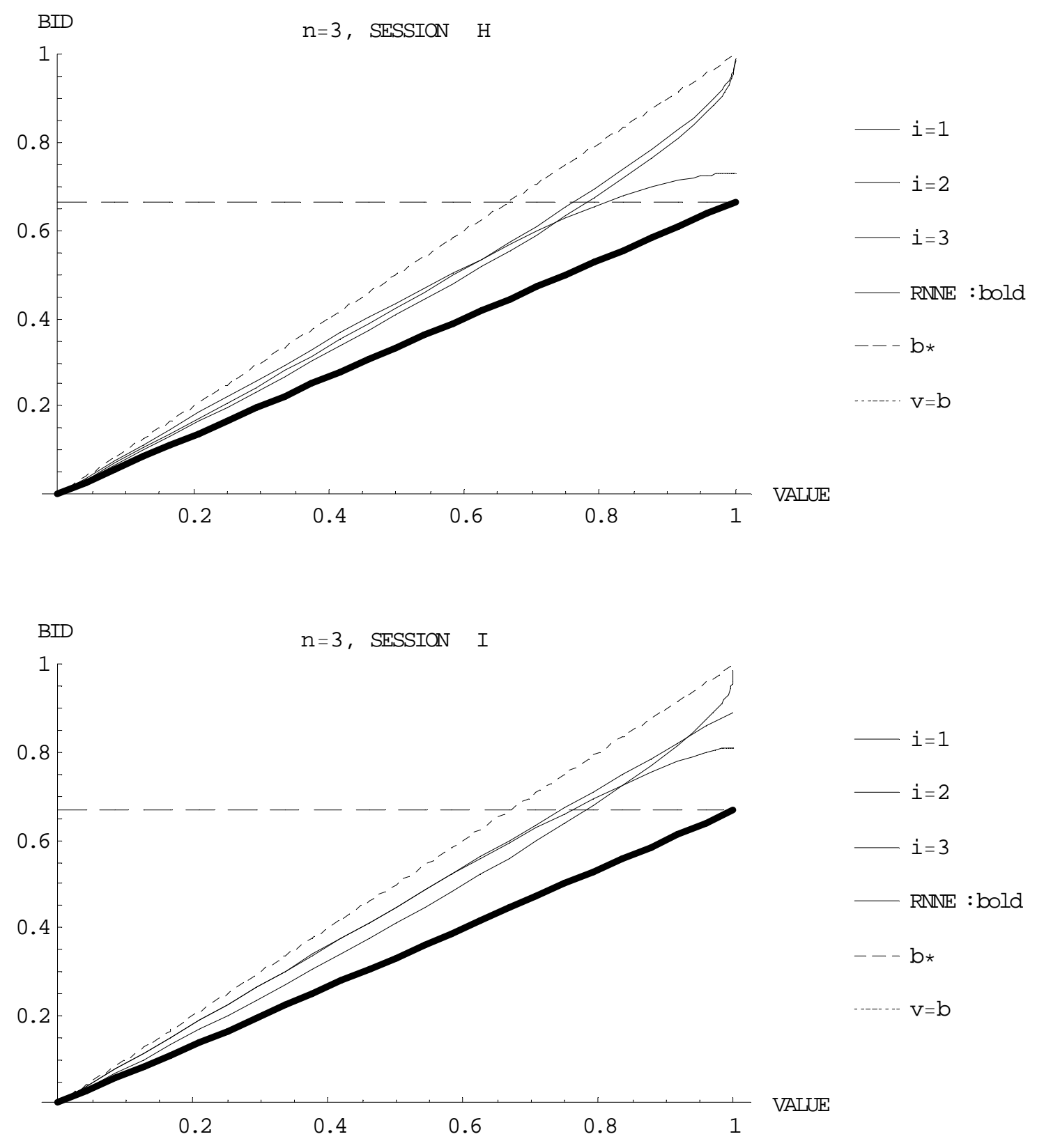
Figure 2(b): Estimated Bid Functions for Sessions

with Heterogeneous CRRA Bidders --- $n=4(i=1,2,3,4)$
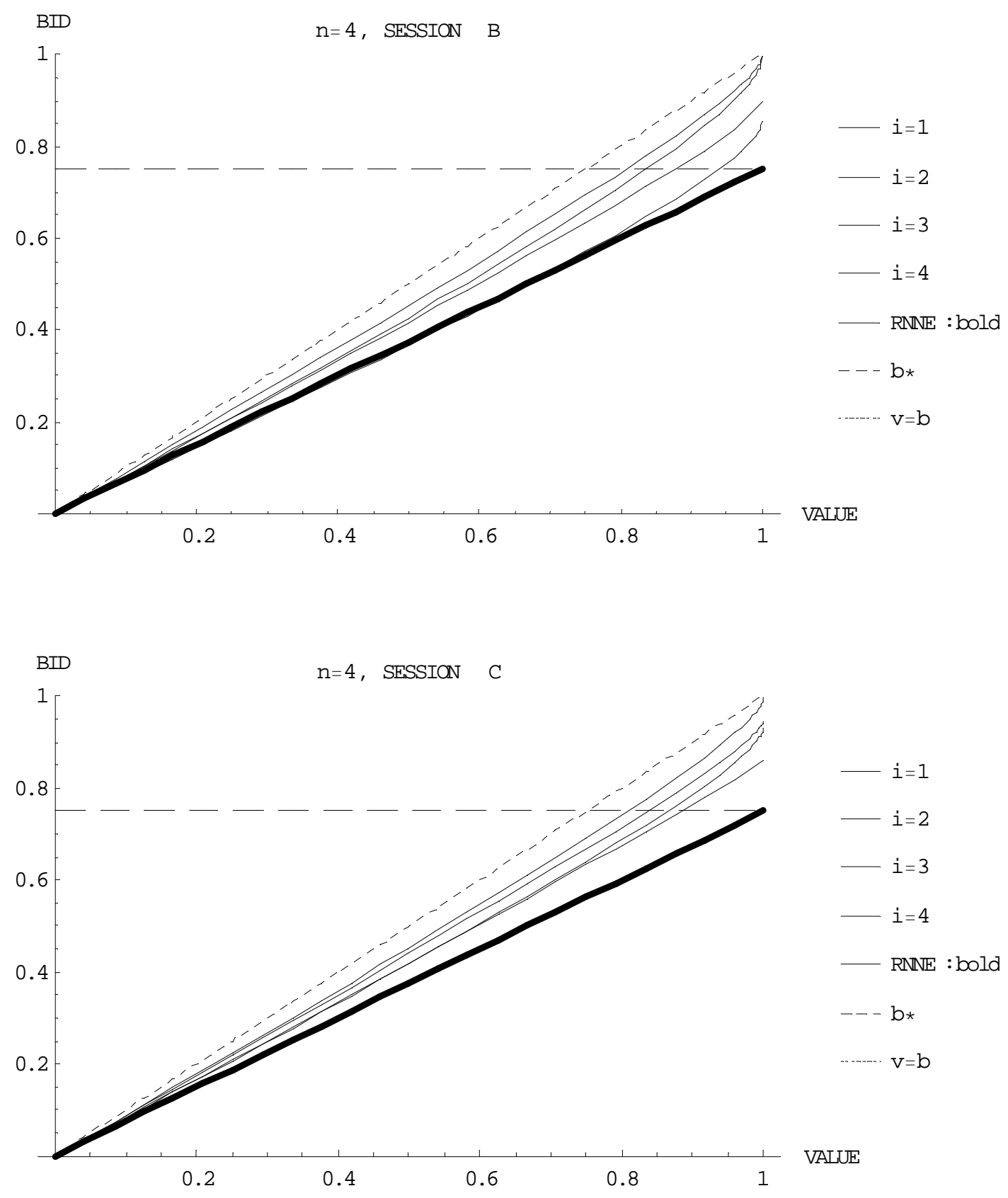
Figure 2(b): (Continued)
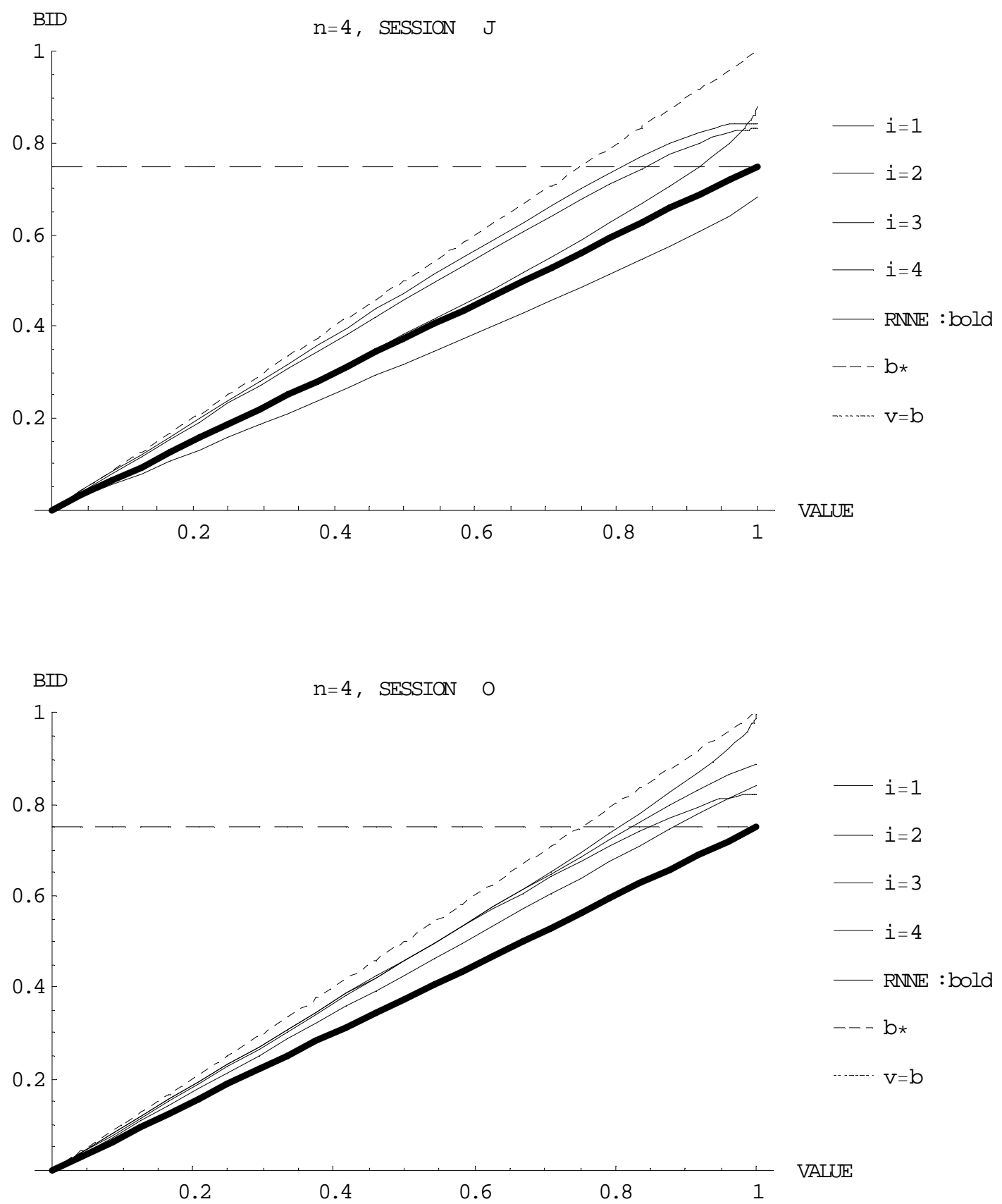
Figure 2(c): Estimated Bid Functions for Sessions

with Heterogeneous CRRA Bidders --- $n=5(i=1,2,3,4,5)$
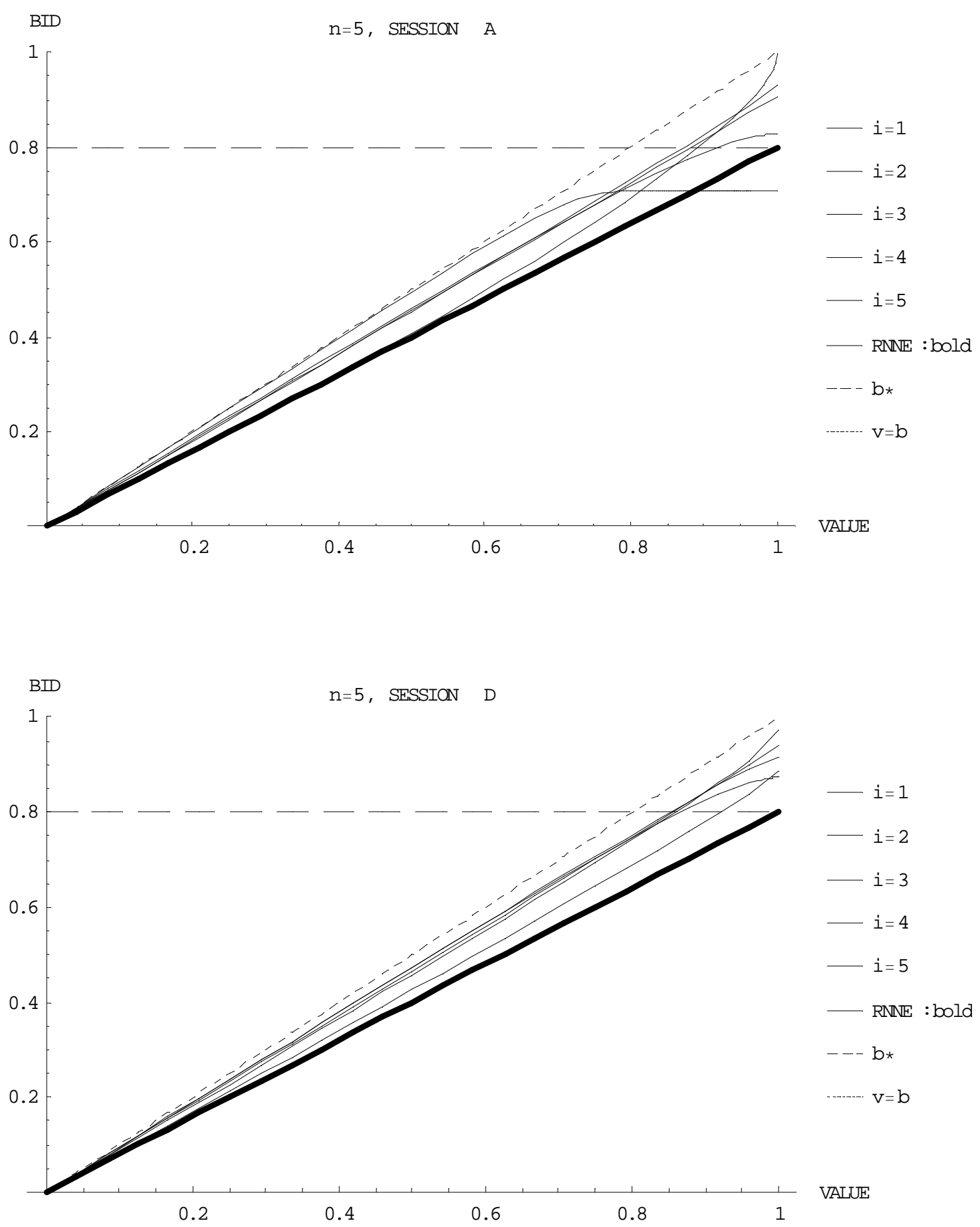


\subsection{Robustness Checks}

In this section we assess the general hypothesis of a Nash equilibrium behavior with constant relative risk aversion and we check the robustness of our structural inferences to the presence or not of outliers and to various information conditions.

We first check whether the data can be fitted by a Nash equilibrium model that assumes either homogenous or heterogeneous constant relative risk attitudes. As such a test would not distinguish sessions with RASNE bidders from sessions with CRRA bidders, it can be seen as a loose assessment of the Nash equilibrium model for constant relative risk attitudes. Using the statistics reported in Table 2, we conduct the Binomial test on the total number of non-rejections of the RASNE and the CRRA models and we find that we cannot reject the general hypothesis of Nash equilibrium bidding with constant relative risk attitudes at $\alpha=.15$ (one-tailed). This holds if the test is conducted separately on the data of the upper, the middle or the lower panel of Table 2 . Hence, there would be evidence that the data support the hypothesis that subjects bid as if they are bidding in equilibrium and as if they all display either homogenous or heterogeneous constant relative risk attitudes.

However, the estimation of (4') with individual dummy variables identified a total of 91 outliers, representing $3.9 \%$ of all observations. ${ }^{11} \mathrm{We}$ conducted the analysis of the previous section without outliers and report the test outcomes in the last column of Table II in Appendix 2. According to the Binomial test, our conclusions remain unchanged for auctions that were conducted with 3 and 5 bidders and with 4 bidders and Design A, but we overwhelmingly reject both models for auctions

\footnotetext{
${ }^{11}$ We defined an outlier as an observation that lies above the $75 \%$ sample quartile plus 2.5 times the inter-quartile range or if it lies below the $25 \%$ sample quartile minus 2.5 times the inter-quartile range. If the samples of observations were Gaussian, the relative frequency of such outliers would be of 2 in 100.000 . We found 3, 84 and 7 outliers in 510 , 1360 and 450 observations from sessions with $n=3,4$ and 5, respectively.
} 
with 4 bidders that were conducted with Design B (see Table $2 *$ of Appendix 2). ${ }^{12}$ Therefore, as a consequence of discarding outliers from the analysis, we also reject the general hypothesis of Nash equilibrium bidding with constant relative risk attitudes to explain overbidding in auctions with 4 bidders at a one-tailed $\alpha=.05$. This holds for sessions that are conducted with Design B and whether the test outcomes are pooled or not.

The use of structural methods to analyze experimental data also allows us to assess the sensitivity of structural inferences to various information conditions. On the one hand, if we cannot observe the individual valuations, as it is typically the case when analyzing field auction data, the estimation of $F_{0}$ can be achieved either by integrating out the unobservable valuations analytically (Paarsch $(1992,1997))$ or by using simulation based techniques (Laffont, Ossard and Vuong (1995)) or by inverting the bidding function in equilibrium (Guerre, Perrigne and Vuong (2000) and Athey and Haile (2002)). In all cases, we can reasonably conjecture that if we cannot observe valuations then the estimates will be less precise and the tests will have less power than if valuations are observed, as in our case. This is because these approaches assume bidders to act in equilibrium and consist in estimating the parameters of the unknown distribution of valuations without assuming the existence of an error term to capture bidders' possible trial-and-error behavior, as $w_{i t}$ in equation (4) and (4'). We therefore expect that the absence of this error term would inflate the variance of the parameter estimates and lead to less rejections of the models tested.

On the other hand, if we were to estimate the RASNE model without having information on bidders' identities to test the homogeneity hypothesis, then we would analyze aggregate behavior and assess the RASNE model only with $H_{0}^{1 \beta}$. Within such a framework, the statistics of Tables I, II and III in Appendix 2 indicate that we cannot reject $H_{0}^{1 \beta}$ for 7 sessions with 3 bidders out of 10, in 9

\footnotetext{
${ }^{12}$ The statistics in Table II of Appendix 2 also indicate that we now reject the CRRA model for session $\mathrm{J}$ with $n=4$, which previously passed the consistency-check although one bidder significantly underbid.
} 
sessions with 4 bidders out of 16 and in 4 sessions with 5 bidders out of 6 so that, according to the Binomial test, we would not reject this model for auctions with $n=3,4$ or 5 at $\alpha=.70$, one-tailed. This holds if we conduct the analysis only for sessions with inexperienced bidders and no tripled payoffs (at $\alpha=.60$, one-tailed) or separately for each experimental design. Thus, when compared to the inferences made from the previous analyses, it appears that not being able to check the homogeneity hypothesis can substantially affect ones' assessment of the RASNE model.

Finally, if we assume that in addition to not being able to test the homogeneity hypothesis, we only know that bidders' valuations are drawn from the unit interval, then we would not be able to reject Vickrey's (1961) benchmark model for risk neutral bidders, whether $n=3,4$ or 5 . This is because we would estimate (4') with no restrictions to test on the estimated parameters. As a consequence of this, we would conclude erroneously that all bidders in a given session draw their valuations from the same Beta distribution $B\left(\theta_{1}, \theta_{2}\right)$ with $\theta_{1}>0$ and $\theta_{2}>0$, and that this Beta distribution is usually different from one session to another. In this case, the check of the homogeneity hypothesis would affect some of our inferences since it would lead to a rejection of this benchmark model for auctions with 4 bidders. Indeed, the statistics of Table II in Appendix 2 indicate that we cannot reject the homogeneity hypothesis in only 4 sessions out of 16 so that both the model's basic hypothesis of a homogenous behavior and the RNNE model itself would be rejected at $\alpha=.10$, one-tailed. This holds also for sessions with 4 inexperienced bidders and no tripled payoffs and for sessions that were conducted with Design B.

\section{Conclusion}

In this paper we report a structural re-examination of a large amount of experimental data on firstprice auctions with private independent valuations. We identify conditions to test the Nash equilibrium models of bidding for homogenous and for heterogeneous constant relative risk aversion 
when bidders have uniformly drawn valuations. Our approach allows us to assess the type of heterogeneity in bidders' behavior, to estimate individual bid functions and to check for their consistency with the received predictions.

Our results confirm the findings reported in the literature of an overbidding and of a heterogeneous behavior which conflicts with the Nash equilibrium prediction for homogenous constant relative risk bidders. However, they indicate that the procedure used to conduct some of the experiments may have affected the bidders' behavior. They also indicate that the usual explanation for overbidding that assumes heterogeneous constant relative risk averse attitudes does not consistently explain the behavior observed in auctions with 3 and 4 bidders. We explain rejections of the Nash equilibrium models for homogenous or heterogeneous risk attitudes by the presence of nonlinearities in subjects' bid functions that do not support the theoretical predictions.

With reference to the use of structural methods to analyze auction data, our study shows the importance of the homogeneity hypothesis when testing symmetric first-price auction models and it puts in perspective the sensitivity of structural inferences to the information available to the researcher. 


\section{References}

Athey S. and P.A. Haile (2002), "Identification of Standard Auction Models", Econometrica, forthcoming.

Campo S., E. Guerre, I. Perrigne and Q. Vuong (2000), "Semiparametric Estimation of First-Price Auctions with Risk Averse Bidders", mimeo, University of Southern California.

Campo S., I. Perrigne and Q. Vuong (2001), "Asymmetry in First-Price Auctions with Affiliated Private Values", Journal of Applied Econometrics, forthcoming.

Chen K.-Y. and C.R. Plott (1998), "Nonlinear Behavior in Sealed Bid First Price Auctions", Games and Economic Behavior, 25, 34-78.

Cox J.C. and R.L. Oaxaca (1996), "Is Bidding Behavior Consistent with Bidding Theory for Private Value Auctions", in R. Mark Isaac (ed.), Research in Experimental Economics, vol. 6, Greenwich, CT: JAI Press, pp 131-148.

Cox J.C., B. Roberson and V.L. Smith (1982), "Theory and Individual Behavior of First-Price Auctions", in V.L. Smith (ed.), Research in Experimental Economics, Vol. 2, Greenwich, CT: JAI Press, 1-43.

Cox J.C., V.L. Smith and J. Walker (1982), “Auction Market Theory of Heterogeneous Bidders", Economics Letters, 9(4), 319-325.

Cox J.C., V.L. Smith and J. Walker (1983), “Tests of a Heterogeneous Bidder's Theory of First-Price Auctions", Economics Letters, 12(3-4), 207-212.

Cox J.C., V.L. Smith and J. Walker (1985), "Experimental Development of Sealed-Bid Auction Theory; Calibrating Controls for Risk Aversion", American Economic Review (Papers and Proceedings), 75(2), 160-165.

Cox J.C., V.L. Smith and J. Walker (1988), "Theory and Individual Behavior of First-Price Auctions", Journal of Risk and Uncertainty, 1, 61-99.

Cox J.C., V.L. Smith and J. Walker (1992), “Theory and Misbehavior of First-Price Auctions: Comment”, American Economic Review, 82(5), 1392-1412.

Donald S. and H.J. Paarsch (1993), "Piecewise Maximum Likelihood Estimation in Empirical Models of Auctions", International Economic Review, 34,121-148.

Friedman D. (1992), "Theory and Misbehavior of First-Price Auctions: Comment", American Economic Review, 82(5), 1374-1378.

Goeree J.K., C.A. Holt and T.R. Palfrey (2002), “Quantal Response Equilibrium and Overbidding in Private-Value Auctions", Journal of Economic Theory, forthcoming. 
Gourieroux C. and A. Monfort (1995), Statistics and Econometrics Models, Vol.2, Cambridge University Press.

Guerre E., I. Perrigne and Q. Vuong (2000), "Optimal Nonparametric Estimation of First Price Auctions", Econometrica, 68(3): 525-574.

Harrison G.W. (1989), "Theory and Misbehavior of First-Price Auctions", American Economic Review, 79, 749-762.

Harrison G.W. (1990), "Risk Attitudes in First-Price Auction Experiments: A Bayesian Analysis", Review of Economics and Statistics, 541-546.

Harrison G.W. (1992), “Theory and Misbehavior of First-Price Auctions: Reply", American Economic Review, 82(5), 1426-1443.

Hendricks K. and H.J. Paarsch (1995), "A Survey of Recent Empirical Work Concerning Auctions”, Canadian Journal of Economics, 403-426.

Holt C.A. (1980), "Competitive Bidding for Contracts under Alternative Auction Procedures", Journal of Political Economy, 88(3), 433-445.

Isaac R.M. and J.M. Walker (1985), "Information and conspiracy in sealed bid auctions", Journal of Economic Behavior and Organization, 6, 139-159.

Kagel J.H. (1995), “Auctions: A Survey of Experimental Research" in Handbook of Experimental Economics, Kagel J.H. and Roth A.E. (eds), Princeton University Press

Kagel J.H., R.M. Harstad and D. Levin (1987), "Information Impact and Allocation Rules in Auctions with Affiliated Private Values: A Laboratory Study", Econometrica, 55(6), 1275-1304.

Kagel J.H. and A.E. Roth (1992), "Theory and Misbehavior of First-Price Auctions: Comment”, American Economic Review, 82(5), 1379-1391.

Laffont J.-J. (1997), "Game Theory and Empirical Economics: the Case of Auction Data”, European Economic Review, 41, 1-35.

Laffont J.-J., H. Ossard and Q. Vuong (1995), "Econometrics of First-Price Auctions", Econometrica, 63(4), 953-980.

Laffont J.-J. and Q. Vuong (1993), "Structural Econometric Analysis of Descending Auctions", European Economic Review, 37, 329-341.

Li T., I. Perrigne and Q. Vuong (2000), "Structural Estimation of the Affiliated Value Model", RAND Journal of Economics, forthcoming.

Maskin E. and J. Riley (2000), "Equilibrium in Sealed High Bid Auctions", Review of Economic Studies, 67, 439-454. 
Paarsch H.J. (1992), "Deciding Between the Common and Private Value Paradigms in Empirical Models of Auctions", Journal of Econometrics, 51, 191-215.

Paarsch H.J. (1997), "Deriving an Estimate of the Optimal Reserve Price: An Application to British Columbia Timber Sales", Journal of Econometrics, 78, 333-357.

Van Boening M.V., S.J. Rassenti and V.L. Smith (1998), "Numerical Computation of Equilibrium Bid Functions in a First-Price Auction with Heterogeneous Risk Attitudes", Experimental Economics, 1, 147-159.

Vickrey W. (1961), "Counterspeculation, Auctions, and Competitive Sealed Tenders", Journal of Finance, 16, 8-37.

Walker J.M., V.L. Smith and J.C. Cox (1987), "Bidding Behavior in First-Price Sealed Bid Auctions; Use of Computerized Nash Competitors", Economics Letters, 23, 239-244.

Walker J.M., V.L. Smith and J.C. Cox (1990), "Inducing Risk-Neutral Preferences: An examination in a Controlled Market Environment", Journal of Risk and Uncertainty, 3, 5-24. 


\section{Appendix 1: Proofs of Propositions}

\section{Proof of Proposition 1}

By definition, we have $\varphi\left(\left(\theta_{1}, \theta_{2}\right), v, 1\right)=v-\int_{0}^{v}\left[\frac{B_{\theta}(s)}{B_{\theta}(v)}\right]^{n-1} d s$ and $\varphi((1,1), v, r)=v-\frac{v r}{n+r-1}$.

Therefore $\varphi((1,1), v, r)=\varphi\left(\left(\theta_{1}^{*}, \theta_{2}^{*}\right), v, 1\right)$ if and only if

$$
\int_{0}^{v}\left(\frac{B_{\theta^{*}}(s)}{B_{\theta^{*}}(v)}\right)^{n-1} d s=\frac{v r}{n+r-1}
$$

Differentiating both sides, we get

$$
\frac{B_{\theta^{*}}(v)^{2(n-1)}-\partial_{v} B_{\theta^{*}}(v)^{n-1} \int_{0}^{v} B_{\theta^{*}}(s)^{n-1} d s}{B_{\theta^{*}}(v)^{2(n-1)}}=\frac{r}{n+r-1}
$$

Re-arranging terms, we get

$$
1-\frac{r}{n+r-1}=\frac{\partial_{v} B_{\theta^{*}}(v)^{n-1}}{B_{\theta^{*}}(v)^{n-1}} \int_{0}^{v}\left(\frac{B_{\theta^{*}}(s)}{B_{\theta^{*}}(v)}\right)^{n-1} d s
$$

Using (A1), we have

$$
\frac{\partial_{v} B_{\theta^{*}}(v)^{n-1}}{B_{\theta^{*}}(v)^{n-1}}=\frac{n-1}{v r}
$$

Integrating both parts out, we get

$$
\begin{aligned}
\int_{v}^{1} d \ln B_{\theta^{*}}(s) & =\frac{1}{r} \int_{v}^{1}(1 / s) d s \\
\ln B_{\theta}(v) & =\frac{1}{r} \ln (v)
\end{aligned}
$$

so that

$$
B_{\theta}(v)=\frac{\Gamma\left(\theta_{1}+\theta_{2}\right)}{\Gamma\left(\theta_{1}\right) \Gamma\left(\theta_{2}\right)} \int_{0}^{v} t^{\theta_{1}-1}(1-t)^{\theta_{2}-1} d t=v^{1 / r}
$$

(A2) holds only for $\theta_{1}^{*}=1$ and $\theta_{2}^{*}=1 / r$. 


\section{Proof of Proposition 2}

To simplify notation, $\theta$ will denote the log-parameters which are denoted by $\tilde{\theta}$ in the text. Taking a Taylor expansion of $S_{n T}\left(\theta_{0}\right)$ around $\hat{\theta}$, we get

$$
\frac{1}{\sqrt{n T}} S_{n T}\left(\theta^{0}\right) \#-\frac{1}{n T} \frac{\partial^{2} S_{n T}\left(\theta^{0}\right)}{\partial^{2} \theta} \sqrt{n T}\left(\hat{\theta}-\theta^{0}\right)
$$

By the central limit theorem, the left hand side of (B1) converges to $N\left(0, I_{0}\right)$. Further, since $\frac{1}{n T} \frac{\partial^{2} S_{n T}\left(\theta^{0}\right)}{\partial^{2} \theta} \stackrel{\text { a.s. }}{\longrightarrow} J_{0}$ we have

$$
\sqrt{n T}\left(\hat{\theta}-\theta^{0}\right) \stackrel{d}{\longrightarrow} N\left(0, J_{0}^{-1} I_{0} J_{0}^{-1}\right)
$$

Under the null hypothesis in (5), it holds that $h\left(r_{0}\right)=\theta^{0}$. Defining $S_{n T}^{*}(r)=S_{n T}(h(r))$, a Taylor expansion of $S_{n T}^{*}(r)$ around $r_{0}$ yields

$$
0=\frac{1}{\sqrt{n T}} \frac{\partial S_{n T}^{*}(\widehat{r})}{\partial r} \# \frac{1}{\sqrt{n T}} \frac{\partial S_{n T}^{*}\left(r_{0}\right)}{\partial r}+\frac{1}{\sqrt{n T}} \frac{\partial^{2} S_{n T}^{*}\left(r_{0}\right)}{\partial r \partial r^{\prime}}\left(\hat{r}-r_{0}\right)
$$

Defining $h_{r_{0}}=\partial_{r} h\left(r_{0}\right)$, using $\frac{1}{n T} \frac{\partial S_{n T}\left(\theta^{0}\right)}{\partial \theta} \stackrel{\text { a.s. }}{\longrightarrow} 0$ and re-arranging terms in (B2), we get

$$
\sqrt{n T}\left(\hat{r}-r_{0}\right) \#\left(h_{r_{0}} J_{0} h_{r_{0}}^{\prime}\right)^{-1} h_{r_{0}} \frac{1}{\sqrt{n T}} \partial_{\theta} S_{n T}\left(\theta^{0}\right)
$$

Using (B1), we have

$$
\sqrt{n T}\left(\hat{r}-r_{0}\right) \#\left(h_{r_{0}} J_{0} h_{r_{0}}^{\prime}\right)^{-1} h_{r_{0}} J_{0} \sqrt{n T}\left(\hat{\theta}-\theta^{0}\right)
$$

Defining $\hat{\theta}^{0}=h(\hat{r})$, a Taylor expansion of $\sqrt{n T}\left(h(\hat{r})-h\left(r_{0}\right)\right)$ around $r_{0}$ yields

$$
\sqrt{n T}\left(\hat{\theta}-\theta^{0}\right) \# h_{r_{0}} \sqrt{n T}\left(\hat{r}-r_{0}\right)
$$

Hence, from (B5) and (B3), $\hat{\theta}^{0}$ and $\hat{\theta}$ are linearly related so that

$$
\begin{aligned}
\sqrt{n T}\left(\hat{\theta}^{0}-\theta^{0}\right) & =h_{r_{0}}^{\prime}\left(h_{r_{0}} J_{0} h_{r_{0}}^{\prime}\right)^{-1} h_{r_{0}} J_{0} \sqrt{n T}\left(\hat{\theta}-\theta^{0}\right) \\
& =P_{h} \sqrt{n T}\left(\hat{\theta}-\theta^{0}\right)
\end{aligned}
$$

Since $\sqrt{n T}\left(\hat{\theta}-\hat{\theta}^{0}\right)=\sqrt{n T}\left(\hat{\theta}-\theta^{0}\right)-\sqrt{n T}\left(\hat{\theta}^{0}-\theta^{0}\right)$, re-arranging terms in (B6) yields 


$$
\sqrt{n T}\left(\hat{\theta}-\hat{\theta}^{0}\right)=M_{h} \sqrt{n T}\left(\hat{\theta}-\theta^{0}\right)
$$

Now, $\theta^{0}$, i.e. the true value of the parameters, is a vector $\left(\theta_{1}^{0}, \theta_{2}^{0}\right)$, and under the null in (5) it must hold that $\theta_{2}^{0}=0$, while, $\theta_{1}^{0}=-\ln \left(r_{0}\right)$. Thus, $h_{r_{0}}{ }^{\prime}=\left(-1 / r_{0}, 0\right)$ and

$$
M_{h}=\left(\begin{array}{cc}
0 & \frac{-j_{12}}{j_{11}} \\
0 & 1
\end{array}\right)
$$

where $j_{i k}$ stands for the element in row " $i$ " and column " $k$ " of $J_{0}$. From (B7) and (B8) it follows that

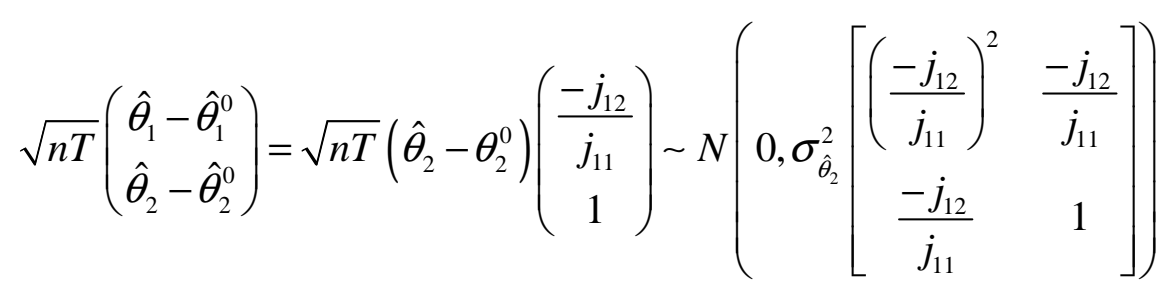

Define

$$
\aleph=n T\left(\hat{\theta}_{1}-\hat{\theta}_{1}^{0}, \hat{\theta}_{2}-\hat{\theta}_{2}^{0}\right) \sigma_{\hat{\theta}_{2}}^{2}\left[\begin{array}{cc}
\left(\frac{-j_{12}}{j_{11}}\right)^{2} & \frac{-j_{12}}{j_{11}} \\
\frac{-j_{12}}{j_{11}} & 1
\end{array}\right]^{+}\left(\begin{array}{c}
\hat{\theta}_{1}-\hat{\theta}_{1}^{0} \\
\hat{\theta}_{2}-\hat{\theta}_{2}^{0}
\end{array}\right)
$$

From (B9), the statistic follows a chi-squared distribution with one degree of freedom (which is the rank of the variance matrix in (B9)) under the null. Using (B7) and (B8) and applying the definition of the Moore-Penrose generalized inverse, we eventually get

$$
\boldsymbol{\aleph}=\left[\frac{\hat{\theta}_{2}}{\sigma_{\hat{\theta}_{2}}}\right]^{2}
$$

which square root follows a $\mathrm{N}(0,1)$ distribution. 


\section{Appendix 2: Tables}

The lower panel of Tables I, II and III report the estimation results for sessions with experienced and/or triple payoffs.

Table I: NLLS estimation results for $n=3$ (rejection probabilities)

\begin{tabular}{|c|c|c|c|c|c|c|c|c|c|}
\hline Session & id & $\begin{array}{c}\# \\
\text { obs }\end{array}$ & $H_{0}^{0}{ }^{\mathrm{a}}$ & $\begin{array}{l}H_{0}^{1 \beta \mathrm{b}} \\
H_{0}^{1 \alpha \mathrm{c}}\end{array}$ & $\hat{\theta}_{1}$ & $\hat{\theta}_{2}$ & $\begin{array}{l}H_{0}^{2 \beta \mathrm{d}} \\
H_{0}^{2 \beta^{*} \mathrm{e}}\end{array}$ & $r^{\mathrm{f}}$ & $\begin{array}{c}\text { \# outliers } \\
H_{0}^{2 \beta^{* *} \mathrm{~g}}\end{array}$ \\
\hline $\mathrm{dfd} 3$ & $\mathrm{~A}$ & 30 & .4588 & $\begin{array}{l}.0682 \\
.1584\end{array}$ & 7.53 & 12.73 & $\begin{array}{c}.1030 \\
---\end{array}$ & --- & $\begin{array}{c}0 \\
---\end{array}$ \\
\hline fdf3' & B & 60 & .3110 & $\begin{array}{l}.2387 \\
.4803\end{array}$ & 1.12 & 1.23 & $\begin{array}{c}.5250 \\
---\end{array}$ & 1.0 & $\begin{array}{c}0 \\
---\end{array}$ \\
\hline dfd10' & $\mathrm{C}$ & 30 & .4526 & $\begin{array}{l}.9181 \\
.2274 \\
\end{array}$ & 1.28 & 1.03 & $\begin{array}{c}4910 \\
--- \\
\end{array}$ & 1.0 & $\begin{array}{c}3 \\
.3210 \\
\end{array}$ \\
\hline fdf10 & $\mathrm{D}$ & 60 & .4514 & $\begin{array}{l}.1215 \\
.0639\end{array}$ & 1.23 & 1.28 & $\begin{array}{c}.8990 \\
---\end{array}$ & .81 & $\begin{array}{c}0 \\
--- \\
\end{array}$ \\
\hline fpn3(1) & E & 60 & .0000 & $\begin{array}{l}.9674 \\
.0000\end{array}$ & 2.07 & 1.01 & $\begin{array}{l}.0077 \\
.0109\end{array}$ & --- & $\begin{array}{c}0 \\
--- \\
\end{array}$ \\
\hline fpn3(2) & $\mathrm{F}$ & 60 & .0178 & $\begin{array}{l}.2646 \\
.0000 \\
\end{array}$ & 2.93 & 1.37 & $\begin{array}{l}.0009 \\
.0000 \\
\end{array}$ & --- & $\begin{array}{c}0 \\
--- \\
\end{array}$ \\
\hline dfd10x & $\mathrm{G}$ & 30 & .0001 & $\begin{array}{l}.0019 \\
.0010\end{array}$ & 1.68 & 1.98 & $\begin{array}{l}.0000 \\
.0000\end{array}$ & --- & $\begin{array}{c}0 \\
---\end{array}$ \\
\hline fpn3(1)x & $\mathrm{H}$ & 60 & .0187 & $\begin{array}{l}.7379 \\
.0000\end{array}$ & 2.77 & .79 & $\begin{array}{l}.1560 \\
.1050\end{array}$ & {$[.62]$} & $\begin{array}{c}0 \\
--\end{array}$ \\
\hline fpn3(2)x & I & 60 & .0000 & $\begin{array}{l}.9951 \\
.0000 \\
\end{array}$ & 3.31 & 1.00 & $\begin{array}{l}.0001 \\
.9760 \\
\end{array}$ & [.32] & $\begin{array}{c}0 \\
--- \\
\end{array}$ \\
\hline fpn3(3)x & $\mathrm{J}$ & 60 & .0053 & $\begin{array}{l}.0130 \\
.0000\end{array}$ & 5.10 & 2.69 & $\begin{array}{l}.0000 \\
.0001 \\
\end{array}$ & --- & $\begin{array}{c}0 \\
--- \\
\end{array}$ \\
\hline
\end{tabular}

Note: Null hypotheses tested. ${ }^{\mathrm{a}}: \theta_{1 i}=\theta_{1 j}$ and $\theta_{2 i}=\theta_{2 j}, \forall i \neq j ;{ }^{\mathrm{b}}: \theta_{2}=1 ;{ }^{\mathrm{c}} H_{0}^{1 \alpha}: \theta_{1}=1$; ${ }^{\mathrm{d}}: \theta_{2 i}=1, \forall i ;{ }^{\mathrm{e}}: \theta_{2 i^{*}}=1, \forall i ;{ }^{\mathrm{f}}$ : Estimated risk averse parameter (set equal to 1 if $H_{0}^{1 \alpha}$ cannot be rejected at $\alpha=10$, two-tailed) [Estimated risk parameters for sessions that did not reject $H_{0}^{2 \beta^{*}}$ ];

${ }^{\mathrm{g}}: \theta_{2 i^{*}}=1, \forall i$ when outliers are discarded. 
Table II: NLLS estimation results for $n=4$ (rejection probabilities)

\begin{tabular}{|c|c|c|c|c|c|c|c|c|c|}
\hline Session & id & $\begin{array}{c}\# \\
\text { obs }\end{array}$ & $H_{0}^{0}{ }^{\text {a }}$ & $\begin{array}{l}H_{0}^{1 \beta \mathrm{b}} \\
H_{0}^{1 \alpha \mathrm{c}}\end{array}$ & $\hat{\theta}_{1}$ & $\hat{\theta}_{2}$ & $\begin{array}{l}H_{0}^{2 \beta \mathrm{d}} \\
H_{0}^{2 \beta^{*} \mathrm{e}}\end{array}$ & $r^{\mathrm{f}}$ & $\begin{array}{c}\# \\
\text { outliers } \\
H_{0}^{2 \beta^{* *} \mathrm{~g}} \\
\end{array}$ \\
\hline $\mathrm{dfd} 8^{\prime}$ & $\mathrm{A}$ & 40 & .1725 & $\begin{array}{l}.3734 \\
.0000\end{array}$ & 2.50 & 1.17 & $\begin{array}{c}.5500 \\
---\end{array}$ & .40 & $\begin{array}{c}0 \\
---\end{array}$ \\
\hline fdf8 & B & 80 & .0000 & $\begin{array}{l}.1661 \\
.0094 \\
\end{array}$ & 1.57 & .65 & $\begin{array}{l}.2670 \\
.2916 \\
\end{array}$ & [.66] & $\begin{array}{c}0 \\
--- \\
\end{array}$ \\
\hline fp1onci-1 & $\mathrm{C}$ & 100 & .0587 & $\begin{array}{l}.0989 \\
.0000\end{array}$ & 1.98 & .61 & $\begin{array}{l}.8120 \\
.8277\end{array}$ & {$[.52]$} & $\begin{array}{c}2 \\
.0443\end{array}$ \\
\hline fp1onci-2 & $\mathrm{D}$ & $88^{\dagger}$ & .0000 & $\begin{array}{l}.0168 \\
.0000\end{array}$ & 15.20 & 6.89 & .0000 & --- & $\begin{array}{c}12 \\
.0000\end{array}$ \\
\hline fp1onci-3 & $\mathrm{E}$ & 100 & .0129 & $\begin{array}{l}.0000 \\
.0000 \\
\end{array}$ & 4.01 & 2.91 & $\begin{array}{l}.0000 \\
.0000 \\
\end{array}$ & --- & $\begin{array}{c}3 \\
.0000 \\
\end{array}$ \\
\hline fp1onci-4 & $\mathrm{F}$ & 100 & .0096 & $\begin{array}{l}.0000 \\
.0000 \\
\end{array}$ & 10.23 & 5.09 & $\begin{array}{l}.0201 \\
.0000\end{array}$ & --- & $\begin{array}{c}11 \\
.0023 \\
\end{array}$ \\
\hline fp1onci-5 & $\mathrm{G}$ & 100 & .0000 & $\begin{array}{l}.0000 \\
.0000\end{array}$ & 12.79 & 5.49 & $\begin{array}{l}.0000 \\
.0000\end{array}$ & --- & $\begin{array}{c}3 \\
.0078\end{array}$ \\
\hline fp1onci-6 & $\mathrm{H}$ & 100 & .1371 & $\begin{array}{l}.1376 \\
.0000 \\
\end{array}$ & 2.58 & 1.57 & $\begin{array}{c}.1540 \\
--- \\
\end{array}$ & .39 & $\begin{array}{c}4 \\
.0002 \\
\end{array}$ \\
\hline fp1onci-7 & $\mathrm{I}$ & 100 & .0000 & $\begin{array}{l}.5527 \\
.0000\end{array}$ & 4.88 & .72 & $\begin{array}{l}.0086 \\
.0089\end{array}$ & --- & $\begin{array}{c}11 \\
.0069\end{array}$ \\
\hline fp1onci-8 & $\mathrm{J}$ & 100 & .0000 & $\begin{array}{l}.2019 \\
.0305 \\
\end{array}$ & 1.82 & 1.32 & $\begin{array}{l}.5590 \\
.5590\end{array}$ & [.59] & $\begin{array}{c}9 \\
.0254 \\
\end{array}$ \\
\hline fp1onci-9 & $\mathrm{K}$ & 100 & .0000 & $\begin{array}{l}.7301 \\
.0000\end{array}$ & 3.02 & 1.14 & $\begin{array}{l}.0000 \\
.0041\end{array}$ & --- & $\begin{array}{c}13 \\
.0000\end{array}$ \\
\hline fp1onci-10 & $\mathrm{L}$ & 100 & .2131 & $\begin{array}{l}.0000 \\
.0000 \\
\end{array}$ & 10.43 & 5.23 & $\begin{array}{c}1200 \\
--- \\
\end{array}$ & --- & $\begin{array}{c}14 \\
.0000 \\
\end{array}$ \\
\hline dfd8x & $\mathrm{M}$ & 40 & .0000 & $\begin{array}{l}.3353 \\
.0077\end{array}$ & 2.06 & 1.24 & $\begin{array}{l}.0016 \\
.0258\end{array}$ & --- & $\begin{array}{c}0 \\
---\end{array}$ \\
\hline fdf8'x & $\mathrm{N}$ & 80 & .0003 & $\begin{array}{l}.6694 \\
.0000 \\
\end{array}$ & 1.95 & .94 & $\begin{array}{l}.0152 \\
.0295 \\
\end{array}$ & --- & $\begin{array}{c}1 \\
.0056 \\
\end{array}$ \\
\hline dfd8x* & $\mathrm{O}$ & 40 & .0449 & $\begin{array}{l}.0257 \\
.0000\end{array}$ & 3.45 & 1.40 & $\begin{array}{l}.1010 \\
.2064\end{array}$ & {$[.45]$} & $\begin{array}{c}0 \\
--- \\
\end{array}$ \\
\hline fdf8' $x^{*}$ & $\mathrm{P}$ & 80 & .4503 & $\begin{array}{l}.1548 \\
.0000 \\
\end{array}$ & 2.21 & 1.23 & $\begin{array}{c}.5550 \\
--- \\
\end{array}$ & .45 & $\begin{array}{c}1 \\
.9698 \\
\end{array}$ \\
\hline
\end{tabular}

Note: ${ }^{\dagger}$ : We discarded outliers from this dataset so that the estimation procedure could converge.

Null hypotheses tested. ${ }^{\mathrm{a}}: \theta_{1 i}=\theta_{1 j}$ and $\theta_{2 i}=\theta_{2 j}, \forall i \neq j ; \quad{ }^{\mathrm{b}}: \theta_{2}=1 ;{ }^{\mathrm{c}}: H_{0}^{1 \alpha}: \theta_{1}=1$; ${ }^{\mathrm{d}}: \theta_{2 i}=1, \forall i ;{ }^{\mathrm{e}}: \theta_{2 i^{*}}=1, \forall i ;{ }^{\mathrm{f}}$ : Estimated risk averse parameter (set equal to 1 if $H_{0}^{1 \alpha}$ cannot be rejected at $\alpha=10$, two-tailed) [Estimated risk parameters for sessions that did not reject $H_{0}^{2 \beta^{*}}$ ]; ${ }^{\mathrm{g}}: \theta_{2 i^{*}}=1, \forall i$ when outliers are discarded. 
Table III: NLLS estimation results for $\boldsymbol{n}=\mathbf{5}$ (rejection probabilities)

\begin{tabular}{|c|c|c|c|c|c|c|c|c|c|}
\hline Session & id & $\begin{array}{c}\# \\
\text { obs }\end{array}$ & $H_{0}^{0}{ }^{\mathrm{a}}$ & $\begin{array}{l}H_{0}^{1 \beta \mathrm{b}} \\
H_{0}^{1 \alpha \mathrm{c}}\end{array}$ & $\hat{\theta}_{1}$ & $\hat{\theta}_{2}$ & $\begin{array}{l}H_{0}^{2 \beta \mathrm{d}} \\
H_{0}^{2 \beta^{*} \mathrm{e}}\end{array}$ & $r^{\mathrm{f}}$ & $\begin{array}{c}\text { \# outliers } \\
H_{0}^{2 \beta^{* *} \mathrm{~g}}\end{array}$ \\
\hline $\mathrm{dfd} 9$ & A & 50 & .0501 & $\begin{array}{l}.4576 \\
.0029\end{array}$ & 2.43 & 1.22 & $\begin{array}{l}.4530 \\
.5678 \\
\end{array}$ & [.47] & $\begin{array}{c}2 \\
.2310\end{array}$ \\
\hline fdf9' & B & 100 & .0000 & $\begin{array}{l}.4574 \\
.0000\end{array}$ & 2.46 & 1.17 & $\begin{array}{l}.0036 \\
.0000\end{array}$ & --- & $\begin{array}{c}0 \\
---\end{array}$ \\
\hline dfd9* & $\mathrm{C}$ & 50 & .2742 & $\begin{array}{l}.2137 \\
.3671\end{array}$ & 1.43 & 1.55 & .5200 & 1.0 & $\begin{array}{c}0 \\
---\end{array}$ \\
\hline fdf9'* & $\mathrm{D}$ & 100 & .0001 & $\begin{array}{l}.5198 \\
.0000\end{array}$ & 2.70 & .84 & $\begin{array}{l}.6850 \\
.6985\end{array}$ & [.41] & $\begin{array}{c}3 \\
.6380\end{array}$ \\
\hline dfd9'x & $\mathrm{E}$ & 50 & .0000 & $\begin{array}{l}.0024 \\
.0000\end{array}$ & 3.68 & 1.78 & $\begin{array}{l}.0007 \\
.0036\end{array}$ & --- & $\begin{array}{c}0 \\
---\end{array}$ \\
\hline fdf9x & $\mathrm{F}$ & 100 & .0004 & $\begin{array}{l}.0002 \\
.0000\end{array}$ & 3.79 & 2.00 & $\begin{array}{l}.0003 \\
.0004\end{array}$ & --- & $\begin{array}{c}2 \\
.0000\end{array}$ \\
\hline
\end{tabular}

Note: Null hypotheses tested. ${ }^{\mathrm{a}}: \theta_{1 i}=\theta_{1 j}$ and $\theta_{2 i}=\theta_{2 j}, \forall i \neq j ;{ }^{\mathrm{b}}: \theta_{2}=1 ;{ }^{\mathrm{c}}: H_{0}^{1 \alpha}: \theta_{1}=1$;

d: $\theta_{2 i}=1, \forall i ;{ }^{\mathrm{e}}: \theta_{2 i^{*}}=1, \forall i ;{ }^{\mathrm{f}}:$ Estimated risk averse parameter (set equal to 1 if $H_{0}^{1 \alpha}$ cannot be rejected at $\alpha=.10$, two-tailed) [Estimated risk parameters for sessions that did not reject $H_{0}^{2 \beta^{*}}$ ];

${ }^{\mathrm{g}}: \theta_{2 i^{*}}=1, \forall i$ when outliers are discarded.

Table 2*: Frequencies of Non-Rejection and Binomial Test Outcomes [Analysis without Outliers]

\begin{tabular}{|c|c|c|c|c|c|c|c|}
\hline & $\begin{array}{l}\text { Sessions } \\
\text { with }\end{array}$ & $\begin{array}{l}\text { Exp. } \\
\text { Design }\end{array}$ & $H_{0}^{0}$ & $\begin{array}{l}\text { RASNE } \\
H_{0}^{0}+H_{0}^{1 \beta}\end{array}$ & CRRA & $\begin{array}{c}\text { Total \# of } \\
\text { sessions }\end{array}$ & 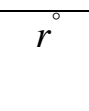 \\
\hline $\begin{array}{c}\text { Inexperienced } \\
\text { Bidders } \\
\& \text { No Tripled } \\
\text { Payoffs } \\
\end{array}$ & $n=4$ & A\&B & $\begin{array}{c}2 \\
(.0193)\end{array}$ & $\begin{array}{c}1 \\
(.0032)\end{array}$ & $\begin{array}{c}1 \\
(.0032)\end{array}$ & 12 & $\begin{array}{c}.40 \\
{[.66]}\end{array}$ \\
\hline $\begin{array}{c}\text { Pooled } \\
\text { Data }\end{array}$ & $n=4$ & $\mathrm{~A} \& \mathrm{~B}$ & $\begin{array}{c}3 \\
(.0107)\end{array}$ & $\begin{array}{c}2 \\
(.002)\end{array}$ & $\begin{array}{c}2 \\
(.002)\end{array}$ & 16 & $\begin{array}{c}.43 \\
{[.56]}\end{array}$ \\
\hline \multirow{2}{*}{$\begin{array}{l}\text { Pooled } \\
\text { by Design }\end{array}$} & \multirow[t]{2}{*}{$n=4$} & A & $\begin{array}{c}2 \\
(.3438) \\
\end{array}$ & $\begin{array}{c}2 \\
(.3438) \\
\end{array}$ & $\begin{array}{c}2 \\
(.3438) \\
\end{array}$ & 6 & $\begin{array}{c}.43 \\
{[.56]}\end{array}$ \\
\hline & & B & $\begin{array}{c}1 \\
(.0107)\end{array}$ & $\begin{array}{c}0 \\
(.0009)\end{array}$ & $\begin{array}{c}0 \\
(.0009)\end{array}$ & 10 & $\begin{array}{c}\text { n.a } \\
\text { [n.a.] }\end{array}$ \\
\hline
\end{tabular}

Note: n.a.: not applicable; Rejection probabilities in parenthesis; ${ }^{*}$ assumes a prior rejection of $H_{0}^{0}$ and no rejection of $H_{0}^{2 \beta^{*}}$ (and of $H_{0}^{2 \alpha^{*}}$ ); :average risk parameter estimate for sessions with RASNE behavior (computed from data in Tables I, II and III in Appendix 2 --- the parameter is set equal to 1 if $H_{0}^{1 \alpha}$ cannot be rejected at $\alpha=.10$, two-tailed); average risk parameter estimates for sessions that did not reject the CRRA model of bidding in brackets. 